\title{
LA REVELACIÓN A LOPE DE SALAZAR
}

JUAN MIGUEL VALERO MORENO ${ }^{1}$

Universidad de Salamanca \& SEMYR

\section{Resumen:}

Edición anotada y comentada de la Revelación a Lope de Salazar, texto inédito del manuscrito 2762 (SA9a) de la Biblioteca Universitaria de Salamanca.

Palabras clave: Revelación, visión, alegoría, poesía de cancionero.

\begin{abstract}
:
Annotated Edition with commentaries of Revelación a Lope de Salazar, unnpublished text from the manuscript 2762 (SA9a) (Salamanca, Biblioteca Universitaria).
\end{abstract}

Keywords: Revelation, vision, allegory, cancionero poetry.

No puedo, en esta ocasión, más que ofrecer un humilde delantal a un texto poco conocido e inédito, la Revelación de Lope de Salazar. La obra debería ingresar en los cauces corrientes y molientes de nuestra historia literaria y eso ha de bastar en un principio. En otro lugar me ocupé de su contexto codicológico y cultural (Valero Moreno, 2003). Ahora ofrezco una edición del texto con notas (elementales) y anexos que deberían resolver algunas dudas y pasos. Quedará por alzar un estudio literario del texto que lo sitúe de forma conveniente en su peculiar tradición y que motive las razones de su existencia y entramado. A los ojos acostumbrados a la visión literaria esta nueva extraña y desubica respecto a ciertos senderos conocidos. Pero, al mismo tiempo, el carácter convencional del poema es indudable. Este dilema, que otrora se remediaba con el marbete tradición y modernidad, deberá ser considerado con mayor experiencia de los textos y sus tradiciones, con la intención de aportar paralelos palmarios de su constitución literaria. El que desee desbrozar trochas por su cuenta, además de estudios clásicos como los de Ch. R. Post (1915) o H. R. Patch (1950), dispone de una tipología específica del género de las revelationes por P. Dinzelbacher (1991), uno de los mayores expertos en la materia, al que se deben numerosos estudios y antologías, como la Mittelalterliche Visionsliteratur (1989). El más amplio estudio histórico, literario y formal respecto de los textos latinos es posiblemente el de C. Carozzi (1994), donde se

1 Universidad de Salamanca. Correo-e: asmodeo@usal.es. Recibido: 01-02-2010; segunda versión: 0304-2010. 
encontrará también una generosa bibliografía. En el ámbito específicamente hispánico la bibliografía es relativamente parca todavía, aunque contamos con trabajos recientes tocantes tanto a la alegoría literaria (estudiada desde siempre con mayor profusión; vid. Sanmartín \& Vidal, 2005) como a las visiones. Una introducción genérica a las visiones románicas puede leerse en Rubio Tovar (1992), y sobre las visiones del otro mundo hispánico es posible desplazarse desde los antecedentes de Berceo (Díaz Díaz, 1985; Merino Castrillo, 2009) a los milagros marianos en el siglo xv (Díaz Tena, 2005). Como proyección específica de la posible lectura de la Revelación que se edita en el ámbito cortesano y femenino me parece de gran interés la propuesta de García-Bermejo (2006).

En 2003 realicé una primera transcripción, de servicio, del texto de la Revelación. Poner de nuevo las manos sobre ella me ha mostrado lo conveniente que es el reposo de determinadas tareas a lo largo de los años. No sólo porque he descubierto errores sonrojantes en aquella copia (que por fortuna no afectan a la base de la argumentación del artículo de entonces), sino porque revela la precariedad de nuestra comprensión de los textos históricos y alumbra la necedad y la soberbia con la que a menudo reflexionamos sobre ellos.

La lectura del texto en el manuscrito, en todo caso, no requiere de habilidades paleográficas o codicológicas extraordinarias, pero tampoco es ninguna bicoca. Se trata de un testimonio único, mientras no se demuestre lo contrario, pero es copia evidente de ese mismo texto y, lo más probable, por las deturpaciones que lo afean, copia de una copia. A los errores o circunstancias materiales de quien o quienes realizaron la copia en el manuscrito 2762 de la Universidad de Salamanca hay que sumar los problemas derivados de su estado de conservación. En amplios sectores la tinta ha traspasado el papel amalgamando las grafías del recto con el verso, lo que perjudica notablemente no pocas lecturas. Los cortes en los bordes han limado, a su vez, parte del texto, ausencias a las que hay que añadir la falta de algunas estrofas o semiestrofas que no figuran, sin que se pueda saber a ciencia cierta el motivo. El último folio vuelto también presenta un estado precario, con un cambio de tinta, y una grafía mucho más cursiva difícil de explicar. ¿Procede de la misma época que el resto del texto (que entonces habría acabado de forma abrupta y extravagante), o bien se añadió mas tarde, valiéndose un revisor del manuscrito de otro texto de la Revelación de donde copió lo que faltaba?

He optado por una transcripción semipaleográfica (salvo en la distinción de grafías para los distintos tipos de "s" alta, sigma..., fundamentalmente). Se indican mediante cursiva los desarrollos de las abreviaturas, y entre paréntesis cuadrados las lecturas reconstruidas. Diversos detalles, cuando no se ven en el cuerpo principal del texto, se comentan en nota, así como la justificación de determinadas lecturas. En unos pocos casos la lectura que presento me sigue pareciendo dudosa, pero lo subrayo, a fin de que otra mente más despejada pergeñe una mejor solución. Acentúo y puntúo según las normas vigentes (siempre que los caracteres me lo permiten), y transcribo con mayúsculas algunos nombres que en el manuscrito no la llevan. Creo que, en conjunto, no modifico nada sustancial que separe al lector de una imagen mental aproximada del contexto originario. 


\section{BIBLIOGRAFÍA}

Carozzi, C. (1994): Le voyage de l'âme dans l'au-delà. D'après la littérature latine (Vè-XIIlè siècle), Roma, École Française de Rome [Collection de l'École Française de Rome, 189].

Díaz Díaz, M. (1985): Visiones del Más allá en Galicia durante la alta Edad Media, Santiago de Compostela, Bibliófilos Gallegos.

Díaz Tena, Ma . E. (2005): “El Otro Mundo en un milagro mariano del siglo xv”, Península. Revista de Estudos Ibéricos, 2: 25-43.

Dinzelbacher, P. (1989): Mittelalterliche Visionliteratur: eine Anthologie, Darmstadt, Wissenschaftliche Buchgesselschaft.

Dinzelbacher, P. (1991): Revelationes, Turnhout, Brepols [Typologie des Sources du Moyen Âge Occidental, 57].

García-Bermejo Giner, M. M. (2006): “Les destinataires de la poésie religieuse castillane du xvè siècle", en Le goût du lecteur à la fin du Moyen Age, Bohler, D. (ed.), París, Le Léopard d'Or [Cahiers du Léopard d'Or, 11]: 171-184.

Merino Castrillo, J. (2009): El viaje al más allá en las literaturas hispánicas hasta Berceo, Logroño, Instituto de Estudios Riojanos [Filología, 25].

Patch, H. R. (1950): The Other World According to Descriptions in Medieval Literature, Cambridge (Mass.), Harvard University Press. Traducción castellana de Hernández Campos, J. (1956): El otro mundo en la literatura medieval, México, Fondo de Cultura Económica. Seguido de un apéndice por Lida de Malkiel, $\mathrm{M}^{\mathrm{a}}$. Rosa, "La visión de trasmundo en las literaturas hispánicas".

Post, Ch. R. (1915): Medieval Spanish Allegory, Cambridge (Mass.), Harvard University Press.

Rubio Tovar, J. (1992): “Literatura de visión en la Edad Media románica: una imagen del otro mundo", Études de Lettres: 53-73.

Sanmartín Bastida, R. y Vidal Doval, R. (eds.) (2005): Las metamorfosis de la alegoría: discurso y sociedad en la Península Ibérica desde la Edad Media hasta la Edad Contemporánea, Madrid, Iberoamericana.

Valero Moreno, J. M. (2003): “La persistencia alegórica. Un poema narrativo dantesco en el corpus de cancioneros salmantinos: la Revelación de Lope de Salazar", en Actes del X Congrés Internacional de l'Associació Hispànica de Literatura Medieval, Alemany, R., Martos, J. Ll. y Manzanaro, J. M. (eds.), Alicante, Universidad de Alicante \& Institut Interuniversitari de Filologia Valenciana [Symposia Philologica], 3: 1539-1557. 



\section{REVELACIÓN QUE FUE MOSTRADA A LOPE DE SALAZAR POR UN ÁNGEL}

\section{Salamanca, BUS Ms. 2762 olim Biblioteca del Colegio Mayor de Cuenca, fols. 73v-78r}

Reuelaçión que fue mostrada a Lope de Salazar por vn ángel ${ }^{1}$

O luz de los jntelectos tu persona trina y vna more en $\mathrm{mj}$, con que diga los secretos que en la tu corte diujna conoçí;

entera

pues fue tan du[l]çe tu pago,

la jnvocaçión non fingida ${ }^{2}$

que hiziere

a ti solo Dios la hago, cuya muerte nos da vjda que no muere.

Tu Santo Spiritu m'alumbre con que pueda poner yo por escrito vn sueño de dulçedumbre quél cuerpo tal me dexó sin spirito ${ }^{3}$.

vna toda

Entre cuyo bien y mal, entre cuya glorja y pena que sintía, vi vna boz angelical más dulçe que de serena, ${ }^{4}$ que dezía:

«Quiero que sepas, amjgo, que aquel rey que a los sujetos da conorte manda que vengas comjgo donde veas los secretos de su corte, no por tú lo merecer de saber la soberana pulcritud, mas por darte a conoç[e]r en qué despendas la vana juventud.»
Asý como despierto, deste sueño glorjoso $\mathrm{m} u$ cho presto ante mjs ojos hallé vn ángel claro, hermoso, cuyo jesto en hermosura s'estrema; su senblante, cuerpo y cara muj gentil con vna rica diadema y una almática más clara que vn veril.

Tomando nuestra jornada como yo sienpre mirava al profundo, vy vna nuve colorada que de gran fuego çercava todo el mundo.

No cesando de mirar al ángel que me gujaua; no me tuve sin poder le preguntar qué cosa sinjficaua aquella nuve ${ }^{5}$.

Respondió: «Sábete, amigo, que la soberuja es aquella que se influye a la que dios es enemigo, la que todo el mundo mella y destruye.

Es aquella, para mjentes, amiga de pensamjentos mundanales, es çevo que a los valientes acarrea los tormentos jnfernales.»

Pasamos más adelante con muchas glorjas y viçios y allegamos a vn palaçio muy triunfante de muy ricos edifiçios, do hallamos tanta jente sin pesar, 
tanta bienaventurança, que memorja

Las torres eran algunas no podría recontar la glorja que allj se alcança de la glorja.

Pregunté al ángel: «Señor, estos bienaventurados, ¿quiénes fueron qu'en aquel mundo traydor tan exçelentes estados mereçieron?»

Responde el ángel |74ra

«Estos son los labradores que sus cuerpos con sus manos mantenjan y los sus pobres sudores con los pobres sus hermanos los partía $n »^{6}$.

Señor ángel, si ser puede, sy pueden tus benefiçios, si tú puedes, haz que con estos me quede, no quiero de mjs serujçios más merçedes.

$\mathrm{Y}$ aqueste ruego te ofresco pues aquel es el biujr de mi vida; no porque yo lo merezco, mas por no me ver morjr a la partida.»

Dize el ángel

"Andemos, que si te alexas desta glorja que te falta hallarás que la glorja que les dexas no es nada con la más alta que verás.» Así que quando partimos desta sala que publico tan real, súbitamente nos vimos en vn alcáçar muy rrico desigual.||74rb de jaspes mucho lunbrosos, laboradas en los medios sus colunas de balajes muy preçiosos rodeadas de rica maçonería, de mjll maneras de joyas sus varandas, de preçiosa pedrería los raçimos, claraboyas y gujrnaldas.

De oro todo el tejado de quien su obra galana se publica. El suelo todo esmaltado, las puertas de filjgrana mucho rica.

Las paredes de cristales, un rrico verjl en medio de su cunbre, a quien ojos corporales no podían dar remedio de su lunbre.

Mjrando aquella trebuna desta sala tan dorada del que adoro, vy a la entrada vna coluna de letras toda gravada hechas d'oro.

Pregunté al que me gujava qué lavores de letras era aquella y qué ystorja recontava su thenor?

Responde el ángel.

«Sepas que todos los honbres qu'en la vida justa biuen y s'ençierrart en la tjerra, en esta tienen sus nonbres, en esta sola se'escryuen y s'ençierra $n^{8}$.

Y aquel qu'en pecado cae, aquel que su bien derribe 
con su mal,

su nonbre desta se rrae y en el jnfierno s'escryve en otra tal».

Entramos en otra sala que sus obras esmeradas y primor no se allega nj yguala njnguna de las pasadas en dulçor; por do pasan muchas jentes de toda cavtiujdad mucho francas sus caras claras, luzientes sus ropas, de castidad todas blancas.

Allí vi los religiosos que del mundo refrenaron su cudiçia, muchos reyes generosos que sus reynos governaron en justiçia.

Muchas dueñas limosneras que la hanbre sus pedaços les matavan; quánto las vi delanteras, quán claros aquellos braços que lo davan. | |74vb

Allí vi de los menores, ${ }^{9}$ de los baxos ynoçentes infinjtos, mas destos grandes señores, destos ricos y potentes, muy poqujtos ${ }^{10}$.

Allí vi más exçelentes los acá más desechados de consuno;

mas ponposos y valientes nj grandes enamorados no njnguno.

Andauan las santas almas por jardines y vergeles olorosos entre plátanos y palmas, çinamomos y laureles glorjosos

cantando con gran mjsterio, loando su majestad muy a tenpre.

$\mathrm{O}$ bendito el catiuerjo que nos dio tal libertad para sienpre.

De los aspros çiliçios y ábitos y cordones que traximos, de tan pequeños serujçios, o quán grandes galardones reçibimos.

En cuyo coro glorjoso jamás çesa este loor tan solene daquel dios tan anjmoso que en tanta glorja y dulçor los sostiene. |75ra

Muy ledos y sin casançio en fin de nuestro camino çelestial

llegamos al gran palaçio donde estaua el vno y trino filial.

Las obras y maravillas $\mathrm{d} e$ salas y corredores tan de sobra ¿qué lengua podrá dezillas recontando los primores de su obra?

Cuya obra quiero callar pues es tan alto Señor el que sostiene, porque avella de contar a tan rrudo trobador no conviene.

De carvunco los hunbrales era su rica corona rodeada; las almenas de diamantes, el ruedo de calçedonja muy preçiada.

Su rico doser despaldas entallado de sapinas 
y çafires

figurado de esmeraldas, franjado de corverinas y rubíes.

Vi ángeles syn cuento, ordenados sus ofiçios çelestiales, ${ }^{11}$ ante cuyo acatamjento no çesan estos servjçios diuinales. | |75rb

Potestades y virtudes con harpas y chirunbelas glorjosas, serafines con laudes monacordios y viuelas y baldosas; las bozes contras tenores las cançiones que cantauan y tañjan, todas eran de loores para aquel Dios que adoravan y serujan.

Cuyas bozes espeçiales melodías de consuno no çesauan los cantos angelicales; al cabo todos en vno concordauan; yo quéstaua muy contento ante'l diujno y humano poderoso vi que'staua en finamjento vn rrico onbre tirano cudiçioso.

Cómo su alma salió d'entre hijos y muger y de honbros tan presto se la lleuó el hanbrjento Luçifer en las manos ${ }^{12}$; mas los ángeles llegaron con $\mathrm{m} u$ chas alegaçiones a la vez y tal partido sacaron que fuesen con sus razones ante'l juez $^{13}$. | 75va
Llegando al sol de justiçia, llegando al rey diujnal verdadero,

movido con gran cudicia dixo el prínçipe infernal el primero:

«Bien sabes, eterno Dios que desque nos destruyste, justo rrey, entre estas gentes y Nós bien sabes que'stableçiste aquesta ley:

$\mathrm{Q} u^{\prime} e l$ crudo avarjento rico fuese a aquel fuego disforme sin clemençia.

A tu Alteza supljco con esta ley que conforme tu sentençia».

El ángel que le fue dado para que guarda le fuese dixo asý: «Jamás cometió pecado, que prjmero no le dixese guay de ti.

Mas pues fue su voluntad de juntar sienpre riqueza sin prouecho, si qujsiere con piedad, si no juzgue tu Alteza por derecho». Quando el justo juez vio cada vno lo que dezía, justamente su sentençia pronunçió, en la qual se contenja lo siguiente:

"Anda, ve, triste, maldita, pues que nunca oviste duelo de mjs pobres, a aquella pena ynfinjta donde la glorja del çielo nunca cobres». La sentençia pronunçiada, sin grado de apelaçión nj rreujsta, 
tomaron a la cujtada, no menguada de afliçión, y conqujsta

lleuáronla todos ellos a aquellas penas eternas con abraços, los vnos por los cabellos y los otros por las piernas y los braços ${ }^{14}$.

Otro juyzio

De aqueste lugar glorjoso vi feneçer a desora sjn su voto vn perverso religioso que fue de Nuestra Señora muj devoto así como fue botada su alma para jamás deste mundo, así se vio sobarcada del caudillo Satanás del profundo.

Mas llegó aquella espera $n c ̧ \mathrm{a}^{15}$ que los suyos no son no sé cuyos, aquella que sjn tardança su corte en la tal pasjón a los suyos |76ra con vna ganosa curia con aquel representar muy lunbrante, con vna graçiosa furia con vn hermoso mudar de senblnte.

dize Nuestra

Señora al Enemjgo ${ }^{16}$ : «Di, traydor, ¿quién te mandó all'alma poner temores deste onbre, de quien sienpre me sirujó, de qujen sienpre $\mathrm{d}[\mathrm{i}]$ o loores a mj nonbre?

Anda, mal aventurado, para aquel fuego sin calma con porfía, pues osaste ser osado de querer llevar all'alma qu'era mja».

Responde con mjedo el metido en grandes ardores: «O, Señora, sienpre nos fuiste cruel por ser de los pecadores defensora» ${ }^{17}$

\section{Dize Nuestra Señora}

«No quiero yo que te quexes nj menos que en el abismo me la atizes, mas quiero que me la dexes hasta que vamos al mjsmo que tú dizes.

Y con esto soy contenta que deljbre el Alto Justo la questión»; do con gana muy hambrienta dixo aquel dragón robusto su rrazón:

«Bien sabes, Justo Juez, que pues que con tus manos ||76rb el mundo y su redondez sobre todos los humanos tú nos diste

dinidad y esecutores d'aquellos que corronpiesen tu mandado $\mathrm{d}^{\prime}$ aquellos que su[s] herrores jamás nunca conoçiesen su pecado, y en guarda desta ordenança por ser a todos njvel justo, llano, posiste peso y valança en poder de San Miguel y en su mano

donde sus viçios mundanos fueron tantos que pesauan 
sin medida,

los méritos tan liujanos que muy claro se mostrauan ser perdida $»^{18}$.

Aquella Reyna a quien plaze hazernos más benefiçios que queremos, aquella luz que nos haze más merçedes ${ }^{19}$ que serujçios le hazemos, ante aquel dragón cruel, infernal engañador de qujen huyó, tomó la boz por aquél, avnque jndigno pecador, siervo suyo.

Ante la eterna presençia d'aquel su hijo Hemanuel Rey del çielo, con solene reuerençia los ojos puestos en él y en el [suelo] ${ }^{20} \mid 76$ va ante aquel mereçimjento ante aquella grante jnmensa que parjó con aquel acatamjento la Virgen nuestra defensa començó.

«O mj bien y mj holgura, o hijo cruçificado por jndinos, no deshagas tu hechura pues de vida syn pecado no son dignos.

Mas acuerda la virtud que ardida en huego de amor te jncljnó

a comprarles la salud, pues sabes quánto dolor nos costó» ${ }^{21}$.

Y tú dexiste: «Señor, por tu santa boca y çierta no reçiba de mj muerte el pecador, mas quiero que se convierta por que biua.

Pues fue mjo tan propinco suplico a tu poder

y a tus plagas,;

la menor de todas çinco te dirá con gran rrazón lo que hagas.

No hermoseo sus pecados, nj que este mucho herrara no lo njego, mas si no oviera culpados nj tu muerte aprouechara nj mj ruego, así que en fin de rrazones por estas razones dos sin valança te suplico le perdones os ça» ${ }^{23} \cdot|| 76 \mathrm{vb}$

Dize el enemigo:

«Yo, Señor, no sé qué diga con rrazón nj con maljçia nj querella, pues cobré tal enemjga que no me vale justiçia contra ella; sé que lleuo mal proçeso, del qual espero quedar sin prouecho, mas con todo nj por eso más tengo de rremontar mj derecho.

Si les diste saluaçión para que libres quedasen dentrevalos fue con esta condiçión: que los buenos se saluasen y no los malos.

Esta ley no le defiende, antes le dexa confuso tu pasión, porque su salud se entiende al que en tus dolores puso el coraçón. 
Quanto más que éste en la vida nunca fue de bien hazer su jntinçión;

pues digo que a la partida

no le deve de valer

contriçión

porque tú libres les das

sus sentidos, su memorja,

su aluedrjo;

por estas causas y más

te muestro, Rey de la glorja,

comø que $e^{24}$ es mjo».|77ra

Anbas las partes oýdas quanto quisieron dezir

y alegar

sus rrazones esprjmjdas

en hilo de discutir

y pronunçiar,

el oydor onjpotente,

aquel verdadero padre

que escuchaua,

respondió muj dulçemente

a aquél ruego que su madre

le rrogaua.

«O tenplança de mjs sañas, o luz que tan claros pone sus sinjestros,

pues soy de vuestras entrañas

gran rrazón es que perdone

yo los vuestros.

No mereçe ser echado

de mj cara vuestro rruego

en mj trono

todo el djcho dexado

por vuestra rrogaria luego

le perdono».

No digamos el tormento

quél diablo lieva y meçe

nj su grjta,

mas aquel gradeçimjento

que a su señora le ofreçe

la bendita.

«O Reyna toda hermosa

tú que'n los juyzios diujnales

nos sostienes

con bondad tan abondosa, que nuestros viçios y males

tornas bienes. || 77rb

Quando ya tan pecador

te hallé tanto çercana

de mj parte

¿qué hará tu servidor

que te sirviere de gana

sin errarte,

o cómo deven loarte

de puro coraçón fuerte

por Señora

quantos biuen, pues sin arte ${ }^{25}$

les eres de cruda muerte

defensora?»

Las rrazones que le dixo

no las qujero rrecontar

porque pienso

sería cuento prolixo

avellas yo de contar

por ystenso ${ }^{26}$,

mas recuent'os el dolor

que sintí ${ }^{27} \tan$ a desora

en oýr

como dixo el gujador:

«Amjgo, sabe qu'es ora

de partir.

Pues as visto el galardón

y la gloria que se alcança

por serujçios,

vamos a ver la pasión

$\mathrm{d}^{\prime}$ aquellos quél mundo engaña

con sus viçios,

que avnque triste por perder

tal glorja sin ygualdad

y salud,

fue forçado de hazer

de pura neçesydad

la virtud». |77va

Refrenando la porfía

de mj dolor lastimero

syn afiçión

con la más fe que podía

hize [a] aquel Dios verdadero

mj oraçión. 


\section{Oraçión}

«O bien de la humanjdad, o justo rrey de sosiego, sin pesares, pues veo tu majestad, agora muérame luego si mandares.

Mas suplícote el biujr quitando el fiero vestiglo de mj boca, no más de para dezir la glorja de aqueste siglo cómo es poca»

Salj con aquel dolor no prestando lo quésfuerça mj adaljd qual sale el batallador quando le arrinca $n^{28}$ por fuerça de la lid.

Tal quedé de la partida de aquella glorja sjn arte tanto leda, qual queda la humana vida quando el alma se le parte y ella queda; así que en fin de rrazones vna senda escura, rrasa, sin claror, nos metió por sus pisadas ${ }^{29}$ de aquella triste casa de dolor.

Do estauan quatro montañas çercadas de muchas rrocas çosufrales, desiertas sierras estrañas do saljan fuego, azeyte, pez y rresina con afán, de las otras çufre çiego rebuelto todo con trementina y alqujtara.

De manera que ljdiavan aquellas huestes entramas en sus guerras y al tienpo que se encontravan más altas yvan las llamas que las sierras ${ }^{30}$.

Allí vi al triste Caýn que mató al su hermano Abel por jnbidia; en aquel fuego sin fin a costa suya y con él sienpre ljdia.

Al traydor jngrato Judas que vendió por mal dinero a su Señor ofreçiendo a penas crudas |78ra $[\ldots]^{31}$

Al caudillo Agamenón $n^{32}$ caudillando aquellas jentes eso de abismo ${ }^{33}$. Al Rey Ajás Talamón ${ }^{34}$, al rico duque de Atenas eso mismo, Deyfebo, Paris ${ }^{35}$, Troylos ${ }^{36}$, su hermano Margarjtón ${ }^{37}$ el menor, ${ }^{38}$ sus gritos llantos oýrlos no menguados de afljçión y dolor.

Tanto qu'es pena dezirlos ver sus lorigas y mallas tan ardientes de aquellos grandes cavdillos que hizieron las batallas tan valientes.

Ver al noble Rey Príamo[s] $]^{39}$ quán esqujua se le dava la pasión; oýr sus grjtos y llantos por mill partes me llagava el coraçón.

Ver al noble que se llama don Héctor, el esforçado cauallero ${ }^{40}$, en el paño de la fama puesto, por más acabado el delantero, la boz ya rronca, cansada 
de los llantos y manzillas; pues sentid, que no le vale el espada con que hizo maravillas en la lid. | | [78rb]

la boz ya rronca, cansada, de los llantos y manzillas ${ }^{41}$.

Romanos con car[ta]genenses en vitorias desyguales se hallaron, $\mathrm{y}$ en fuerças de sus arneses conquistas tan prençipales acabaron.

Sus consejos, sus sabieças, con rrazón se llamarían desconçiertos, pues no vjeron sus altezas los peligros que tenían encubjertos.

No quisyeron conoçer nin sanar de aquesta hiebre, nin adorar a quien les h[a]ze comer a todos en un pesevre sin rrjfar. $[\ldots]^{42}$

\footnotetext{
Allj ui a la Puliçena ${ }^{43}$ en quien fama se da llana de hermosa, la djscreta rreyna Elena ${ }^{44}$ que causó tanta batalla crimjnosa.

Vi la profeta Casandria ${ }^{45}$ espejo de sabidoras y prudentes.

Vi la hermosa Handr[i]a $\dagger^{46}$ entre estas muchas señoras eçelentes ${ }^{47}$. | [78va]

Con cien mjl formas de gritas, con altas lamentaçyones
}

muy conpuestas.

Otras con bozes más chyquas sus músicas y cançiones eran éstas:

«O muerte, ¿cómo no vjenes cruda, por qué nos enbargas tu venida?

Siglo, ¿por qué nos sostjenes? $\mathrm{O}$ djos, ¿por qué nos alargas esta vjda?

O engañoso dios dañoso que las hueste[s] governauas y ferías, ¿Cómo nos vienes tan solo? El socorro que nos dauas y ponjas vsó de nuestras porfjas; o sin cimyenta [sic] castjllo engañador, ¿con qual engaño podjas llamarte nuestro caudillo defensor?»

Fyn 
1 Para la explicitación poética de una visión sirva de testimonio el de la Revelación de un ermitaño que se contiene en los folios $129 \mathrm{v}-135 \mathrm{v}$ del ms. b-IV-21 de la Biblioteca de El Escorial. La rúbrica: "Esta es una revelaçión que acaesçió a un omne bueno hermitaño de santa vida que estava rezando una noche en su hermita e vyo esta revelaçión, el qual luego la escrivió en rymas, ca era sabidor en esta çiençia gaya". La edición más accesible de este texto, auto-fechado en 1382, "E el mes de enero, la noche primera, | En CCCC e veynte, durante la hera", es la de Franchini, E. (2001): Los debates literarios en la Edad Media, Madrid, Laberinto [Arcadia de las Letras, 9]: 253-258, que reproduce con ligeras modificaciones Kraemer, E. von. (1956): Dos versiones castellanas de la "Disputa del alma y el cuerpo" del siglo XIV, Helsinki, Mémorires de la Société Néophilologique, 18.3, 40-53. La Revelación comparte códice con los Proverbios de Sem Tob, la Doctrina de discriçión de Pedro de Veragüe, el primer testimonio conservado en castellano de una Danza de la Muerte y el Poema de Fernán González, cuya inclusión pertenece a una voluntad distinta y a otro orden codicológico distinto del del resto de las composiciones. Ha estudiado con gran detenimiento y astucia este códice Infantes, V. (1997): Las danzas de la muerte. Génesis y desarrollo de un género medieval (siglos XIII-XVII), Salamanca, Universidad de Salamanca [Acta Salmanticensia. Estudios Filológicos, 267]: 226-239.

2 La invocación a la cristiana musa es un tópico de la literatura apologética y se encuentra presente desde los orígenes de la literatura cristiana. En las proximidades de Salazar son numerosos los ejemplos castellanos, como, por ejemplo, la rúbrica que se encuentra en la Pasión trobada, en la que se reprehende los poetas que invocan las sciencias. El pierio subsidio de Mena, verbigracia, lo recoge Santillana en el Infierno de los enamorados, estrofa 2.

3 entera y una toda se refiere a que habría que unir los versos para conformar una toda o entera estrofa. Más adelante van separadas las estrofas, en el manuscrito, por líneas horizontales.

$4 \quad$ Se refiere a la voz de una sirena. Es llamativo el cruce sacro-profano de la asociación ángel-sirena. Por otra parte, Salazar nos dice que vio una voz: la iconografía podría justificar la visualización de la voz a través de filacterias, espíritus, como la paloma que vierte la palabra divina en el oído de Gregorio Magno que, por supuesto, es un oído interior, el gesto, como el famoso del orador, presente al menos desde las iluminaciones de las Etimologías de Isidoro, u otros ingenios. Para la sirena en los poetas de cancionero y las posibles fuentes de este personaje literario véase Kerkhof, M. P. A. M. (2001): “Sobre la sirena en la literatura española del siglo xv", en Studia in honorem Germán Orduna, Funes, L. y Moure, J. L. (eds.), Alcalá de Henares, Universidad de Alcalá: 341-346.

5 El motivo de la 'nube de soberbia' a la que se refiere Salazar, como representación del poder concedido por Dios, puede leerse en Apocalipsis 10 1: "Vi otro ángel poderoso que descendía del cielo envuelto en una nube; tenía sobre su cabeza el arco iris, y su rostro era como el sol, y sus pies como columnas de fuego". Vid. Éxodo 13 21-22; 16 10-12; San Agustín, De Trinitate 214 24. Cf. Libro de miseria de omne, c. 385: "onde dize de la soberbia do Job en su scriptura | que siquier suba al çielo que está en grand altura | o que suba en las nuves que fará ý poca dura, | ca caerá en el estiércol e en suzia podredura"; Job 20: "Si ascenderit ad coleum superbia, et caput eius nubes tetigerit, quasi sterquilinium in fine perdetur". Tomo el texto, retocándolo, de la edición paleográfica de Artigas, M. (1919): "Un nuevo poema por la cuaderna vía", Boletín de la Biblioteca Menéndez y Pelayo, 1: 153-161; cit. 158.

$6 \quad$ El hombre visionario de la Revelación aparece caracterizado como humilde e incluso solicita compartir la bienaventuranza de los labradores. Es el nuevo modelo propuesto a partir del siglo XIII, en contraste con los visionarios de la Alta Edad Media, cuyo linaje se prolonga hasta el siglo XII. En consonancia con estas posturas pauperistas queda la declaración explícita de fray Lope de Salazar de no pertenecer a otra alcurnia que la de los «fijos de cavadores», como manifiesta en sus segundas Satisfacciones (art. 11), de hacia finales de 1460, y donde parece renegar de la opinión de aquellos que lo emparentaban con la familia Salinas, ligada a la de los poderosos Haro; vid. ed. Lejarza, F. y Uribe, Á. (1957): “Introducción a los orígenes de la Observancia en España", Archivo Ibero-Americano, 17: 17-945. Puede apreciarse el antiguo modelo al que me refiero en el texto en prosa castellana de la Visio Philiberti o Dialogus inter corpus et animam, poema rítmico latino de finales del siglo XII, donde el ermitaño pertenece a la categoría de los antiguos pobres voluntarios, que habían dejado de lado grandes fortunas o renunciado a las prerrogativas de sus linajes: “Vn omne bueno ermitaño que llamaron Fyliberto era omne de buen lynage, ca deçendía de lynage de rreys de Françia; et consyderando las cosas d'esta vida ser corronpibres et meospreçiándolas propuso de seruir a Dios e perseuerando en el seruiçio de Dios conpuso este lybro en el qual puso e escriuió muy santas palabras de vna uisión que vio...". El primero en editar este texto fue Octavio de Toledo, J. M. (1878): “Visión de Filiberto", Zeitschrift für Romanische Philologie, 2: 41-69. Es esencial el final de la redacción, cuando acaba la visión y Filiberto expone su moralidad. El efecto de la visión del cuerpo devorado por los 
gusanos (que traslaticiamente pueden entenderse por sus pecados) y la condena al Tártaro tienen como consecuencia lógica una transformación espiritual que se propone como modelo a aquellos a los que se destina la revelación. Esta catársis, desde el punto de vista de la predicación, será, a partir sobre todo del siglo XIII y el ascenso de las órdenes menores, el fundamento discursivo de conversiones reales. No se trata de conversiones de una religión a otra, claro, sino del giro de un cristiano hacia una espiritualidad más comprometida $\mathrm{y}$, por lo general, demostrativa. Puede resultar de interés comparar contexto codicológico del texto en prosa, con su versión poética posterior, también en castellano, (compuesta en 1382, según da noticia el propio poema, aunque fijada en un códice de fecha posterior). La versión en prosa sigue a la versión toledana del Libro de buen amor (hoy en la BNM ms. 1469/Vitrina 6-1). La posición co-textual de la versión poética, como se indicó, es más rica, ya que acompaña a textos de índole moral, doctrinal o monitoria como los Proverbios morales de Sem Tob, la Doctrina de la discriçión de Pedro de Veragüe, el primer testimonio vernáculo castellano de la Danza de la Muerte, con la que guarda paralelismos temáticos obvios (vid., por ejemplo, Lucio Basalisco, «La Revelación de un hermitaño e la Danza de la muerte: analogie e differenze», Quaderni di Lingue e Letterature, 17 (1992), págs. 11-19) y el Poema de Fernán González, que pertenece a una unidad codicológica distinta pero que como poema de la cuaderna vía no carece del todo de sentido en esta antología de literatura, en uno u otro grado, doctrinal. Por otro lado, quizás en virtud de su carácter alegórico, el texto se transmitió, más tardíamente, en dos cancioneros de finales del siglo $x v$ en los que se encuentra recogida poesía de algunos de los poetas más representativos de la época de Juan II, como Santillana o Juan de Mena, pero también Juan Rodríguez de la Cámara o Suero de Ribera. Son los manuscritos BNP Esp. 313, f. 179v-181v y BNP Esp. 230, f. 225r-228r., textos todos estudiados y editados por Erik von Kraemer, «Dos versiones castellanas de la Disputa del alma y el cuerpo del siglo XIV», Helsinki: Mémoires de la Société Neophilologique, 18.3, 1956.

$7 \quad$ La descripción del palacio está tomada de la Jerusalén Celeste de Apocalipsis 21 y, en concreto, para el uso de las piedras preciosas, 18-22: «Su muro era de jaspe, y la ciudad, oro puro, semejante al vidrio puro; | y las hiladas del muro de la ciudad eran de todo género de piedras preciosas: la primera, de jaspe; la segunda, de zafiro; la tercera, de calcedonia; la cuarta, de esmeralda; | la quinta, de sardónica; la sexta, de cornalina; la séptima, de crisólito; la octava, de berilo; la novena, de topacio; la décima, de crisoprasa; la undécima, de jacinto, y la duodécima, de amatista. | Las doce puertas eran doce perlas, cada una de las puertas era de una perla, y la plaza de la ciudad era de oro puro, como vidrio transparente". De forma explícita lo hizo, y con abundantes similitudes léxicas, como no podía se de otra manera, en todo caso, fray Ambrosio Montesino en unas coplas de san Juan Evangelista ordenadas por la reina Isabel la Católica: De cómo San Juan vio la disposición y hermosura de la ciudad de Dios: "Después viste la ciudad | del cielo que en ser es una, | que arde toda en caridad | y a su inmensa claridad | no suceden sol ni luna, | mas el Padre y su cordero, | por quien todo se gobierna, | son su norte y su lucero | y su sol más verdadero | de rayos de luz eterna. || Eran fuertes y hermosos | sus cimientos de jacintos | con carbuncos luminosos | y balajes muy preciosos, | entre esmeraldas distintos; | era tan rico su muro | de paredes relumbrantes, | que eran todas de oro puro | y de jaspe verde escuro | con puntas de diamantes. || De argamasa de rubíes | viste ser sus fundamentos, | y doce más de zafires, | anejos a los veriles | eran todos los cimientos; | amatisto y crisopaso | se juntan al artificio, | ¡oh, paraninfo, qué paso | para ser ninguno escaso | de comprar tal edificio! || Era todo el pavimento, | para honra de las faldas, | de cristal de buen asiento | y de muy verde ornamento | de cuadradas esmeraldas, | y tenía en doce puertas | doce perlas margaritas, | no cerradas, mas abiertas, | porque sean descubiertas | sus grandezas infinitas. || $\mathrm{Y}$ viste por maravilla | aquel río cristalino | que manaba de la silla | del cordero sin mancilla | y del Padre de contino, | en cuyas vegas lucientes | daba el árbol de la vida | doce frutos excelentes, | para salud de las gentes, | que preservan de caída.", vv. 631-680 (Rodríguez Puértolas, J. (ed.) (1987): Cancionero de fray Ambrosio Montesino, Cuenca, Excma. Diputación Provincial de Cuenca.

8 En el Apocalipsis se habla de las obras que se encontrarán relatadas en el Libro de la vida. Por otro lado, la columna es un lugar usual, desde la Antigüedad, para la fijación de la memoria, como en el caso de las guerras romanas que se encuentran en columnas como la de Trajano. La palabra historiadas tiene aquí este sentido, además del de dibujadas, lo que sería muy coherente con esta exposición sencilla, digamos que casi franciscana, del otro mundo. La columna, por otra parte, tiene un largo simbolismo, como representación de poder, de comunicación, etc., como casi todos los signos verticales, tal como el árbol.

9 En el sentido ambiguo y posiblemente intencionado de 'frailes menores' y 'pobres'."

10 Pobreza evangélica. Vid. Mateo 19 2326: "Iesus autem dixit discipulis suis: Amen dico vobis, quia dives difficile intrabit in regnum caelorum. Et iterum dico vobis: facilius est camelum per foramen acus transire, quam divitem intrare 
in regnum caelorum. Auiditis autem his, discipuli mirabantur valde, dicentes: Quis ergo poterit salvus esse? Aspiciens autem Iesus, dixit illis: apud homines hoc impossibile est: apud Deum autem omnia possibilia sunt". Y ya ligado con el concepto de redención en las fundamentales palabras de Pablo 1 Corintios 1 26-31: "Videte enim vocationem vestram fratres, quia non multi sapientes secundum carnem, non multi potentes, non multi nobiles: sed quae stulta sunt mundi elegit Deus, ut confundat sapientes: et infirma mundi elegit Deus, ut confundat fortia: et ignobilia mundi, et contemptibilia elegit Deus, et ea quae non sunt, ut ea quae sunt destrueret: ut non glorietur omnis caro in conspectu eius. Ex ipso autem vos estis in Christo Iesu, qui factus est nobis sapientia a Deo, et iustitia, et sanctificatio, et redemptio : ut quemadmodum scriptum est : Qui gloriatur, in Domino glorietur". Éste es uno de los pasajes de Salazar donde más evidente se hace la observancia franciscana de la pobreza evangélica. Fray Ambrosio Montesino la reclamaba como favor para la salvación en unas coplas sobre el glorioso san Francisco dirigidas al cardenal de España Pedro González de Mendoza: "La pobreza voluntaria, | desnuda de toda renta, | es victoria muy plenaria| que de la carne contraria | al flaire menor exenta; | rey lo hace, y heredero | del cielo, que no de cobre, | y seguidor verdadero | de la vida y alto fuero | de Dios pobre. || Muchas órdenes cayeron de sus devotos fervores | por las rentas que adquirieron, | mayores que permitieron | sus primeros fundadores, | e también por el amor | en Dios e en ellas partido | carecen de aquel fervor | con que quiere el redentor ser servido. || La codicia es peligrosa | y pasión vituperable, | ante el mundo vergonzosa | en ante Dios muy criminosa, | odiosa y condenable; | pues los que son ofrescidos | a su Dios en sacrificio, | no conviertan sus sentidos | en los bienes desmedidos, | que es gran vicio. || Pobreza es tesoro puro | y gran bien no conocido; | es del Evangelio muro, | y recambio muy seguro | que da el reino prometido; | es riqueza, sin debate, | raíz de frutos preciosos; | es de nuestra carne mate, | la cual nunca se combate de invidiosos.", vv. 371-410. Tomo de nuevo la edición de Rodríguez Puértolas (1987), que sigue, fundamentalmente, la primera impresión toledana de Juan Vázquez, ca. 1485. Para el ámbito europeo del franciscanismo insertado en las ciudades sigue siendo muy valioso el artículo de Baron, H. (1938): "Franciscan Poverty and Civic Wealth", Speculum, 13: 1-37. Sobre la incidencia del asunto de la pobreza ligada al observantismo franciscano en la poesía de cancionero castellana, véase Beresford, A. M. (1998): "Poverty and (In)justice: Temporal and Spiritual Conflict in a Pregunta by Ferrán Sánchez Calavera (ID 1657)", Cancionero Studies in honour of
Ian Macpherson, Deyermond, A. D. (ed.), Londres, Queen Mary and Westfield College, 1998: 39-52. Una antología de textos del Cancionero de Baena sobre el tema que nos ocupa la ensayó Rozas Ortiz, J. (2001): "Si la pobreza es tan abatida...: pobreza ruinosa frente a pobreza evangélica en el Cancionero de Baena", en Juan Alfonso de Baena y su Cancionero. Actas del I Congreso Internacional sobre el Cancionero de Baena (1999), Baena, Ayuntamiento de BaenaDiputación de Córdoba: 349-358.

11 Las nueve órdenes $u$ oficios angelicales son: ángeles, arcángeles, tronos, dominaciones, principales, potestades, virtudes, querubines, serafines.

$12 \quad C f$. fragmento de Oña de la Disputa del alma y del cuerpo (Archivo Histórico Nacional de Madrid, Clero, carp. 279, n. 22): «so un lenzuelo nueuo | jazié un cuerpo de un muerto; | ell alma era fuora | e fuert mientre que plora; | ell alma es en esida; | desnuda, ca non uestida; [...]» (vv. 10-15). Aunque, efectivamente, la apócope extrema de los versos castellanos conservados del poema, invitan a pensar en una fecha más temprana que la de 1201, momento en que se firma el acta de donación del abad y monasterio de Oña a Miguel Domínguez, es posible que el texto sea contemporáneo a esa fecha un poco más tardía. En primer lugar, porque el texto conservado no es una traducción o adaptación del poema francés, de más de mil versos, que podamos considerar autógrafa, sino que es copia, a las claras, de un texto anterior, y quizás una copia muy fiel. Hay una relación, quizás tenue, entre la donación y la Disputa: el asunto de las disposiciones testamentarias de los moribundos y las donaciones casi preceptivas para el que en la tierra disfrutó de riquezas. Precisamente ése es uno de los reproches principales del alma a su cuerpo: «Nunca fust' a altar | por í buena oferda dar, | ni diezmo ni primencia | ni buena penitencia, [...]» (vv. 30-33).

13 Desde el punto de vista técnico puede consultarse la aproximación de Godding, Ph. (1973): La jurisprudence, Turnhout, Brepols [Typologie des Sources du Moyen Âge, 9]. Desde el punto de vista literario conocemos, en Castilla y en el siglo xv, el juicio alegórico de Minos que resuelve la preeminencia entre tres caballeros de la Antigüedad clásica: Aníbal, Alejandro y Escipión y que, de descendencia italiana, puesto que se trata de una traducción, bien representada en manuscritos castellanos, se resuelve como un tratado político-caballeresco. Otros juicios de carácter profano en la literatura castellana arrancan del poema leonés del siglo XIII Elena y María, de ascendencia románica, relacionados con lo que Lewis llamó alegoría erótica y que son legión, por ejemplo en Francia, con las cortes de amor del Lay Amoureux de Eustache Deschamps, el Paradys d'Amour de Jean Froissart o la 
Messe des Oisiaus de Jean de Condé; pero también en castellano, en la época de los Reyes Católicos, como el Juicio de Amor, resuelto por Cupido, del Comendador Ludueña. Para una historia tradicional de las distintas etapas y temáticas de la alegoría hispánica no se ha sustituido todavía el libro de Post, Ch. R. (1915): Medieval Spanish Allegory, Cambridge (Mass.), Harvard University Press, que no pasa de ser un catálogo que merece ser actualizado y razonado.

14 El debate sobre la misericordia divina, la clemencia clásica, y el libre albedrío, con todos sus temas adjuntos como la predestinación, el peso de la caridad y/o de la fe en la práctica cristiana, etc., es uno de los asuntos teológicos más ampliamente discutidos a lo largo de toda la Edad Media. La postura de Salazar bascula entre el redentorismo, a través de la mediación, asunto que tras la creación del Purgatorio debía corresponder más a este lugar que a la abogacía mariana, y la condenación sin paliativos, como en el caso que acabamos de leer. El tema fue objeto, por supuesto, de predicación. Un modelo valiosísimo, por su copia de ejemplos, se encuentra en uno de los sermones atribuidos a Pedro Marín, relacionado con el círculo intelectual de uno de los nobles de mayor importancia política y cultural del xv, Pedro Fernández de Velasco. Me refiero al número tres de los editados por Cátedra, P. M. (1990): Los sermones atribuidos a Pedro Marín, Salamanca, Universidad de Salamanca [Textos Recuperados, 1]. Este Pedro Marín era dado, aunque ello es habitual en la literatura homilética, a ir más allá de la similitudo y trabajar sobre la malla poética de la alegoría. De hecho demuestra una gran conciencia teórica acerca de los modelos hermenéuticos, de los que se sirve en el cuarto sermón de la edición que utilizo, y que tiene como tema Act 12, 11. Allí, entre los modos de la interpretación, distingue el de la alegoría: "Lo segundo vna cosa puede representar a octra quanto a aquello que auemos de creer. E en esta manera se toma octro sentido spiritual que se llama allegórico, que quiere dezir sentido traýdo en estrañeza. Allegórico, ab alleon, quod varium interpretatur, et go[r]e, quod est deduccio, quasi alliena uel varia deduccio" (146).

15 A partir del siglo $x$ se incrementa la devoción mariana en toda Europa, que encontró un lugar de privilegio para su expansión en los monasterios del siglo XI, en especial a través de San Bernardo de Claraval (1091-1153). La relación con la Virgen a partir de la obra del cisterciense tendrá el carácter humano y próximo de las vírgenes de las iglesias góticas del siglo XIII, época en la que se compilan las colecciones de miracula marianos. La figura materna y femenina de María acaba imponiendo en su trato un estilo afectuoso, menos grandilocuente que el referido a Cristo y de tono más intimista. La Virgen como abogada y defensora de todos los hombres es un lugar común de la literatura y la teología mariana de todos los tiempos. El texto de Salazar es una muestra más. Sin embargo, existieron posturas más rigoristas, como la del sermón trigésimo segundo de Vicente Ferrer pronunciado en Ayllón el día 28 de septiembre de 1411 que "tracta de cómo serán definidos por sentençia los buenos e los malos en el día del joyzio". El tribunal del Juicio Final estará compuesto, tal y como anunciaba figuralmente el de Salomón, el rey más sabio, con Cristo en el centro, como juez, acompañado de su Madre y de consejeros, Pedro, Pablo y otros muchos entre sus discípulos (mientras que en el arte típico del románico Cristo aparece rodeado de los ancianos del Apocalipsis). Los buenos, que se encuentran a la derecha, serán juzgados e ingresados en el reino de los cielos; los malos, que ocupan la margen izquierda, serán juzgados y enviados al Infierno, sin posibilidad de intercesión: "E si los pecadores quisiessen dezyr: - ‘O, Madre de Dios, vos, que sodes Madre de peccadores, ¿dades tal consejo?'. E ella respondería: -'Después que conçebí al mi Fijo glorioso e por ocasión de peccadores só fecha Madre de Dios, e por esto todo tienpo he rogado por ellos fasta agora; e vos, my Fijo, lo sabedes e lo avedes visto'. Dirá Ihesú Christo: -'Verdat es, Madre mía'. Estonçe dirá la Virgen María: -'Agora yo he conplido mi tienpo, que yo ya non só abogada, mas juez con mi Fijo; e, assí, ayan pena'". Los textos a los que me refiero, y otros de carácter escatológico, se encuentran en Cátedra, P. M. (1994): Sermón, sociedad y literatura en la Edad Media. San Vicente Ferrer en Castilla (1411-1412), Valladolid, Junta de Castilla y León. En el sermón trigésimo primero, que trata del Juicio general, ya se había adelantado la idea, en un lugar donde se hace una efectiva compositio loci del tribunal divino: "La terçera parte dize: Tunc sedebit super sedem magestatis sue. Esto es, que estonçe se asentará Dios sobre el trono de la su magestad. Razón es que el juez todo tiempo que da la sentençia se deve asentar; si non, será tenido por ufano. E por esto Ihesú Christo se asentará. Aquí viene una qüestión. Esto es, si Ihesú Christo es asentado, ¿qué diremos de la Virgen María, su madre? E dizen algunos que aquel día la Virgen María [será] de la una parte e sand Juan de la otra con las rrodillas fincadas, que rogarán con los pecadores. Esto es grand error; que aquel día non osarán abrir la boca para rogar por ninguna criatura, nin estarán las rodillas fincadas, mas la Virgen María asentada en una silla al costado de Ihesú Christo. Esto fue figurado en Persida positus est tronus eius, etc. (Quarto Regum II capitulo). Quiere dezir: trono fue puesto al costado de Pérsida". Posiblemente la presencia conjunta de Juan y María provenga de las representaciones de la Pasión. En el primer 
texto castellano en el que se explicita el Juicio de los buenos y los malos ya aparece el carácter de la Virgen, no como juez, pero sí como testigo que no interviene, al contrario que en los Milagros. Me refiero a los Signos que aparescerán antes del juicio final: "Non avrá essi día ningunos rogadores| todos serán callando, justos e peccadores, | todos avrán gant miedo e muy grandes temblores, | pero los de siniestro más grandes e peores", c. 64. Aunque Salazar no se inspiró en el texto berceano ni en su tradición, ésta forma parte del bloque imaginativo que sustenta las descripciones del otro mundo. Los Signa Judicii que están en la base de su difusión europea tuvieron numerosas versiones, y parece que Berceo adaptó las de Pedro Coméstor y Pedro Damián. Vid. Pensado, J. L. (1960): “Los Signa Judicii en Berceo", Archivum, 10: 229-270 y Dutton, B. (1973): "The Source of Berceo's Signos del Juicio Final", Kentucky Romance Quaterly, 20: 247-255.

16 La primera aparición hispánica de carácter dramático y literario documentada de la Virgen como Mater Misericordiae aparece en un fragmento del Liber Mariae del franciscano Gil de Zamora, tutor de Sancho el Bravo, relacionado con la leyenda recogida, por ejemplo, en Jacobo de Varazze, de las cuatro doncellas de Dios, disputatio conocida, también, como Processus Belial; vid. Spurgeon, S. W. y Marchand, J. W. (1988): “A Dramatic Fragment of the Four Daughters of God from Medieval Spain", Neophilologus 72: 376-379. La relación de esta pieza con el concepto de redención la estudió Rivière, J. (1934): Le dogme de la rédemption au début du Moyen-Âge, París, Vrin [Bibliothèque Thomiste, 19], en especial, 309-362.

17 El repertorio de obras, de San Ildefonso a San Bernardo y a los romancistas, que hacen encomio del carácter de mediadora universal de la Virgen, es enorme. Aprovecharé para citar, como ejemplo, un sermón romance castellano de la Edad Media, perteneciente a la Colegiata de San Isidoro de León, que recoge un elenco de gracias y virtudes de la Virgen, entre las cuales "Lo iiii" en que santa María ovo grand gracia ante Dios e avrá para siempre jamás sý es en acabar lo que quiere con Él por los pecadores, e esto en tres maneras: lo primero que es que gana gracias del su fijo Ihesú Christo más que otra criatura ninguna para perdonar los pecadores, Onde más miraglos fallamos della que de ningúnd otro santo. Por ende, dize el doctor sant Bernardo: Sicut fons omnibus sciencibus saciat, sic Maria omnibus ad se clamantibus. Dize el doctor que bien asý como la fuente farta a todos los que han sed, asý santa María es abogada a todos aquellos que la llaman de buen coraçón". Sigue un ejemplo de neto carácter literario. Y más adelante: "ca en el rregno de Dios ay dos partes, el uno es de misericordia e el otro es de justiçia. E la justiçia tómala Dios para sý e la misericordia otórgala a santa María, su madre, para quantos ella quisiere. Onde ella se llama Reyna de misericordia"; en Cátedra, P. M. (2002): Los sermones medievales en romance de la Real Colegiata de San Isidoro de León, Salamanca: Seminario de Estudios Medievales y Renacentistas [Catálogo de la Predicación Hispana Medieval, 2]: 145-146.

18 Falta media estrofa para completar la serie lógica. Puede entenderse como una licencia por tratarse el final de la alocución del diablo. Alude a una tradición escatológica antiquísima conocida como psicostasis. El Libro de los muertos egipcio recoge descripciones de este juicio que son similares a las escenas románicas de numerosos pórticos medievales. El muerto, tras una sucesión de ritos purificadores se presenta ante el tribunal de Osiris, que se encuentra sentado en su trono y acompañado de 42 jueces. En el centro de la sala se fija la balanza donde se pesa el corazón del difunto. Éste realiza una confesión negativa y declara su inocencia. Tras su alocución le es solicitado el corazón que se pesa en la balanza para comprobar si ha habido alguna contradicción. Si es así el alma es atormentada por un variado repertorio teratológico. El motivo del peso se encuentra declarado en el AT, como en Job 31, 6: "Péseme Dios en la balanza justa, y Dios reconocerá mi integridad"; o Daniel 5, 27: "Tú has sido pesado en la balanza y hallado falto de peso". Por fin, en Apocalipsis 2012 se habla del libro de la vida, que será abierto el día del Juicio Final: "Vi a los muertos, grandes y pequeños, que estaban delante del trono; y fueron abiertos los libros, y fue abierto otro libro, que es el libro de la vida. Fueron juzgados los muertos según las obras que estaban escritas en los libros". En la sección B, la más antigua del manuscrito BUS 2762, se encuentra un himno de Pérez de Guzmán a San Miguel Arcángel en el que aparece el habitual motivo de la balanza: Ypno al arcangel mjcael. || | Prínçipe muy exçelente | de la sacra gerarchía | e de aquella monarchía | çelestial presidente | del señor omnipotente | sieruo costante, leal | enemigo capital | de la luçifera gente || quando aquella criatura | que muy clara fue criada | e después por su maluada | presunçión tornada escura | con orgullo e desmesura | dixo: «en Aqujlón porné | mi silla e egual seré | de aquel cuya só fechura». [Is 14, 12-14] || Muchas criaturas bellas | de la angélica natura | sigujeron esta locura | por lo qual se dize dellas | qu'el terçio de las estrellas | cayeron con su doctor | a do nunca mengua ardor | e fuego e fumo e çentellas. [fol. 118 ra]|| Tú, arcángel muy preçioso | primjçia de lealtad | de costançia, fee e verdat | un espeio muy lunbroso | con sello muy vigoroso | ardiente e ynflamado | contra el collegio maluado | fuste fuerte e vigoroso. || [glosa: comodo ceçidisti stella matutina] La estrella matutina | con todo su cruel vando | cayó 
rrela[n]pagueando | al suelo de la centina | donde sufre e rresina | los queman sin piedat | blasfemando su maldat | de la justiçia diujna. | | [glosa: sigujsti santus mjcael] El señor que al maliçioso | non dexa sin punjçión | njn syn rremuneraçión | al leal e virtuoso | punjdo el escandaloso | fizo a ti su alferez santo | e del su collegio tanto | prínçipe muy glorioso. || Porque los sus benefiçios | son de tanta exçelençia | que con grant magnjfiçençia| sobra todos los serujçios | añadiendo más ofiçios | de ti fío la balança | donde por vjrtud se alcança | gloria e pena por viçios [fol. $118 \mathrm{rb}$ ] || vençedor de los maluados, | capitán de los leales | juyzios fuertes e eguales | son en tu peso afinados, | los ynojos ynclinados | te rruego noche e día | que a la señora mja | supliques por mjs pecados. Finaliza en el fol. 118va. La cita de Isaías era frecuente en la literatura homilética, tanto de carácter escatológico como en la relativa a las faltas del cristiano. Así puede leerse, por ejemplo, en el Sermón de los VII pecados mortales editado por Cátedra (2002). La imagen de la balanza fue manipulada en las visiones de ultratumba con fines que podían ser políticos o propagandísticos, como en el curioso caso atribuido a Turpín, que salva de la condenación el alma de su emperador, Carlomagno, al colocar en la balanza las piedras de las Iglesias que éste había hecho levantar. En otra versión muy similar se le atribuye la acción de Turpín al rey Jaime el Conquistador (sant Jaume). La versión del Pseudo-Turpín fue trasladada al catalán en el siglo XV y editada por Riquer, M. de (1960): Història de Carles Maynes e de Rotllà (traducció catalana del segle $X V)$, Barcelona, Biblioteca Catalana d'Obres Antigues. La atribución al rey catalán puede leerse en Amades, J. (1965): Costumari català. El curs de l'any, Barcelona, Salvat, 5: 215: "Conta la llegenda que quan va morir el gran rei En Jaume, el diable se'n volia emportar la seva ànima, puix que deia que en vida havia pecat molt. Seguidament va baixar del cel l'arcàngel sant Miquel, proveït de les seves balances, amb què pesa les ànimes, i seguit d'un gran estol d'àngels. Els àngels van portar només una pedra i una fusta de cada una de les moltes esglésies que el rei havia fet aixecar en les moltes ciutats, viles i pobles reconquerits als moros, i el plat dels àngels va pesar mil vegades més que el dels diables, els quals se' $n$ van haver de tornar cap a l'infern amb la cua entre cames, mentre que l'ànima del gran rei, acompanyada per milers i milers $\mathrm{d}$ 'àngels que havien vetllat per ell, pujava triomfant al cel, semblantment a com s'havia passejat el seu exèrcit triomfant per la terra". Recojo estas últimas noticias del interesante estudio de Maiques Climent, J. (2004): “Les ànimes d'ultratomba: una justificació propagandística", Studi General, 23-24: 143-160. Sobre la tradición clásica del motivo de la balanza véase Staioli, A. (1972): “L'immagine de- lle bilance e il giudizio dei morti», Studi Italiani di Filologia Classica, 44: 41-46.

19 La lógica pide un concepto así, pero no existe signo de abreviación.

20 El texto aparece cortado, pero la lógica permite reconstruir 'suelo'.

21 La relación materno-filial y la mediación mariana aparecen juntas en el más famoso ejemplo de la literatura vernácula, la oración que abre el último canto del Paradiso: «Vergine madre, figlia del tuo figlio, | umile e alta più che creatura, | termine fisso d'eterno consiglio, | tu se' colei che l'umana natura | nobilitasti sì, che'l suo fattore | non disdegnò di farsi sua fattura, | Nel ventre tuo si raccese l'amore, | per lo cui caldo ne l'eterna pace | così è germinato questo fiore. | Qui se' a noi meridiana face | di caritate, e giuso, intra i mortali, | se' di speranza fontana vivace. | Donna, se' tanto grande e tanto vali, | che qual vuol grazia, e a te non ricorre, | sua disianza vuol volar sanz'ali. | La tua benignità non pur soccorre | a chi domanda, ma molte fiate | liberamente al dimandar precorre. | In te misericordia, in te pietate, | in te magnificenza, in te s'aduna | quantunque in creatura é di bontate.», etc.

22 El principio del verso aparece tachado y poco claro. Propongo una posibilidad métricamente plausible. El significado obvio es la encomendación 'a tus llagas', que significan la Pasión y Redención.

23 El texto aparece totalmente recortado en el magen inferior derecho.

24 Tachado al márgen, junto a que.

25 'sin engaño'.

26 El tópico de la brevitas suele acompañar a la poesía alegórica, commo en el Infierno de los enamorados de Santillana, stf. VI.

27 Las dos sílabas aparecen claramente separadas en el manuscrito: 'sin ti'.

28 El sentido es 'arrancan', 'apartan', pero la grafía que se lee en lugar de la segunda 'a' es ' $i$ '.

29 Atención a la rima suelta razones/pisadas.

30 Es de suponer que se refiere a la reacción química producida por la mezcla de los compuestos descritos. La batalla crucial entre los ejércitos celestes y las huestes del mal se describe en Apocalipsis 19 como la batalla de Harmagedón. En 1920 se encuentra cierta proximidad con los versos de Salazar: «fueron arrojados ambos [la bestia y el falso profeta] al lago de fuego, que arde con azufre». 31 Queda en el folio espacio en blanco suficiente para completar los ocho versos que faltan a la estrofa, pero que por un motivo $u$ otro nunca llegaron a copiarse. Cabe la posibilidad de que falte material superior a ocho versos.

32 Agamenón ofreció a su hija Ifigenia en sacrificio. Dante pone su ejemplo junto al bíblico de Jefté, que prometió en sacrificio a Dios lo primero 
que viera tras la victoria, siendo su hija (Paradiso V, vv. 64-72).

33 Las enumeraciones de los héroes y heroínas de la guerra de Troya son ya habituales en la primera poesía de cancionero. Son muy significativos algunos de los casos que se pueden espigar en el Cancionero de Baena. En la composición de Alfonso Álvarez de Villasandino de hacia 1395 [ID 1213] el poeta se dirige a Ruy López Dávalos, el Condestable viejo, haciéndole mención de una enfermedad que le tenía postrado y que quizás finara con su vida. En ese momento, el 'viejo pecador' recuerda la 'estruiçión de Troya', pero ésta no le hace meditar en un posible tránsito, sino que le conduce, socarronamente, a la nostalgia de la vida cortesana. A la realidad brillante del mundo homérico hace contraste la ruda vida pastoril a la que a regañadientes se hace en Lozoya. Desfilan por el dezir Aquiles, Héctor, Pantasilea, Calcas, Ulises, Áyax Talamón, Troilo, Paladio, Policena, Pirro, Eneas... En un contexto que recuerda la muerte se sitúa un dezir de Fernán Pérez de Guzmán como "contemplaçión de los emperadores e reys e prínçipes e grandes señores que la muerte cruel mató e levó d'este mundo, e cómo ninguno non es revelado d'ella" [ID 0197]. Dedica una estrofa a los varones troyanos (5) y otra a las 'dueñas' (8): “Dueñas de linda apostura, | Casandra e Poliçena, | Medea de grand cordura, | e la muy fermosa Elena, ...". Algunas de estas excelentes mujeres aparecen también en la "Cantiga de Pero Ferruz para su amiga", [ID 1431] junto a ejemplos del roman artúrico y los libros de caballerías, del mismo modo que se mencionan a Policena y Elena en el contexto de otra cantiga de Alfonso Álvarez de Villasandino por ruego del Adelantado Pero Manrique, que estaba enamorado de la hija del Duque de Benavente [ID 1155]. La enumeración de Juan Alfonso de Baena [ID 0285], del año 1432, está, en cuanto que dirigida al rey sobre el asunto de las discordias en el reino de Castilla, impostada de seriedad. El compilador del Cancionero enumera el currículo de sus lecturas. Las de tema troyano se encuentran fijadas en las estrofas 27-30 y en ellas le recuerda al rey el poder destructor y mortífero de la guerra: "Yo leí la espantable | e cruel guerra de Troya | do se perdió tanta joya | e gentío innumerable | e morió el venerable, | poderoso rey Priamos | e los dos sus fijos amos: | Paris e Éctor el notable".

34 Hijo del rey de la isla griega de Salamina, Telamón, cuyas tropas condujo a Troya. Tras la muerte del héroe griego Aquiles, Áyax solicitó su armadura. Encolerizado porque no se la concedían pensó en matar a Menelao y Agamenón como venganza, pero Atenea no lo permitió y Áyax murió atravesado por su propia espada.

35 Paris se encuentra, en el círculo de la luju- ria, Inferno V, v. 67, junto a Aquiles y Tristán. Hijo de Príamo y Hécuba fue el responsable directo de la guerra de Troya, tal y como habían vaticinado las profecías.

36 Personaje legendario procedente de la leyenda medieval fijada en el siglo XII (ca. 1160) por Benoît de Sainte-Maure en su Roman de Troie. Troilo, hijo de Príamo, se prometió amor eterno con Crésida, hija del adivino teucro Calcas. Pero Crésida, en el transcurso de la guerra troyana, acabó cediendo al amor del griego Diomedes ("e assí falsó el amor | de Troilos el infante; | Diomedes por señor | fincó e bien andante"; (Menéndez Pidal, R. y Varón Vallejo, E. (eds.) (1934): Historia Troyana en prosa y verso, Madrid, Revista de Filología Española [Anejos RFE, 18]: 10, vv. 151-154), haciendo morir a Troilo de desesperación. La traición de Briseida la cuenta Guido de Colunna en el libro 19 de la Historia destrucionis Troiae (12721287). Una caracterización de Troilo en la versión castellana (1443) de Pedro de Chinchilla de la Historia de Guido de Colunna, trasladada por mandado de don Alfonso Pimentel, conde de Benavente: "Troilo, como quier que grande non fuese de cuerpo, grande fue de coraçón, magnánimo e muy animoso, e en si animosidad ovo mixtión de mucha tenprança; muy amado de las moças, e como él, guardando aquella onestad que devía, se delectava en la conversación d'ellas"; Sigo la edición del manuscrito 326 de la Biblioteca Menéndez Pelayo de Santander, por Peláez Benítez, Mª D. (1998): Madrid, Editorial Complutense, libro 8: 196. El pasaje de Guido es más parco: “Troylus uero, licet fueri corpore magnus, magis fuit tamen corde magnanimus" (Griffin, N. E. (ed.) (1936): Historia destructionis Trojae, Cambridge, Mass., Harvard University Press). El asunto tuvo una gran difusión en la Península, desde la Historia troyana polimétrica (c. 1270) a textos breves que se encuentran en varios códices misceláneos. Caso modélico es el de dos epístolas romances cruzadas por Troilo y Briseida con motivo de sus amores. Las tales han sido atribuidas a Juan Rodríguez del Padrón por ser éste el autor del Bursario, una traducción muy libre de las Heroidas. Su difusión en el siglo XV es notable. El texto aparece a menudo injerido en cancioneros poéticos con algún grado de familiaridad y siempre hacia finales de siglo. En el Cancionero castellano y catalán de París (PN4), o en los Cancioneros castellanos de París (PN8 y PN12) aparece junto a obras de Fernán Pérez de Guzmán e Íñigo López de Mendoza. En el Cancionero castellano de París, BNF, Esp. 313, se inserta entre un grupo muy copioso de poetas, (como en el llamado Cancionero del Conde de Haro, Génova: Bodmer, cód. 45), pero además coincide con PN8 en la inclusión de un texto afín a la Revelación de Salazar, la llamada Revelación de un ermitaño, también conocida como 
Disputa del cuerpo y el ánima (1382). También se encuentra en el Cancionero de San Martino delle Scale (Monreale: San Martino delle Scale, ms. II-B-11), junto a una de las copias de la Comedieta de Pon$z a$. El ensamblaje poético de la historia de Troilo y Briseida en la Polimétrica, de otro lado, fue objeto de análisis por Cátedra, P. M. (1993-1994): “El entramado de la narratividad: tradiciones líricas en textos narrativos españoles de los siglos XIII y XIV", Journal of Hispanic Research, 2: 323-354. El tema creado por Benoît de Sainte-Maure lo consagraron definitivamente para la posteridad Boccaccio y Chaucer, que imitó a éste y dedicó su versión a John Gower, el autor de la Confessio amantis. El Troilo de Chaucer lo editaría más adelante el famoso impresor inglés William Caxton. Ferraresi, A. C. (1976), dedicó unas páginas importantes a la leyenda de Troilo y Briseida en España en su "La Virgen y el fin amor", estudio recogido en $D e$ amor y poesía en la España medieval: prólogo a Juan Ruiz, México, El Colegio de México [Estudios de Lingüística y Literatura, 4]: 119-155.

37 La Historia destructionis Troiae lo menciona como uno de los treinta hijos hijos naturales de Príamo. Paris defendió de una situación apurada a Margaritón y a otros hermanos bastardos en batalla contra los griegos, pero no pudo evitar la muerte de éste (vid. libro 21). En cualquier caso, la mención de este personaje menor atiende únicamente a las necesidades de la rima.

38 No recuerdo la fuente de donde Salazar haya podido extraer que Margaritón era el hermano menor entre los hijos de Príamo. Sin embargo, Troilo sí es considerado el menor de los cinco hijos legítimos de Príamo.

39 Príamo, rey de Troya, hijo de Paris y de Héctor, que lo acompañan en estos versos de inspiración tópica homérica. Príamo tuvo una gran descendencia, tanto de hijos e hijas legítimos como naturales. En la Historia destructionis Troiae de Guido de Colunna se establece esta genealogía, trasladada por Pedro de Chinchilla, y de la que cito sólo el pasaje donde se refiere a algunos de los héroes teucros más notables: "Este Príamo tenía por muger una muy noble dueña, cuyo nonbre Écuba, de la cual cinco fijos e tres fijas tenía, de los cuales el primerogénito Héctor era llamado, cavallero de mucha virtud e de maravillosa e non oída estrenuidat en armas, con muy gran virtud esforçado, de las virtudes del cual muchas cosas en las istorias se cuentan tenidas por luenga memoria, e non sin dubda sean para sienpre rezientes; el segundo fijo, Paris, que por otro nonbre fue llamado Alexandre, más fermoso de los bivientes e más enseñado en el arco e saetas; el tercero Deifebo, varón estrenuo e claro en mucha discreción de consejo; el cuarto, Eleno, ome de mucha ciencia e enseñado en las doctrinas de todas las liberales artes; el quinto e postrimero, Troilo, mancebo muy virtuoso en las batallas de la nobleza e virtud, del cual muchas cosas son istoriadas nin la presenye istoria lo olvida". (Peláez Benítez, 1998: libro 5, 156).

40 Héctor es el modelo de caballero por su sabiduría militar, valor, fuerza, y prudencia. Hijo mayor de Príamo y de Hécuba, murió a manos del fiero Aquiles, encolerizado con éste por haber dado muerte a su inseparable amigo Patroclo.

41 El copista repite estos dos versos en el vuelto. En las estrofas que siguen se aprecia con claridad un cambio de letra, escrita con cálamo más fino y grafía más cursiva.

$42 \quad$ Falta media estrofa.

43 Tercera de las hijas de Príamo y Hécuba, tal y como relata Guido de Colunna. La versión de Pedro de Chinchilla: "La tercera e postrimera, Policena, donzella de maravillosa fermosura e de sin medida especiosidat" (157) o "Policena, fija del rey Príamo, virgen muy tierna, conpuesta de mucha fermosura, ésta fue verdaderamente e verdadero rayo de fermosura, la cual la natura con mucho estudio pintó; la fermosura de la cual declarar por particulares sermones trabajo inútil sería: en fermosura e gesto a toda la especie de las mugeres precedía, en la cual la natura, de las cosas conponedora, ninguna cosa erró, salvo en la aver istituido mortal; es entendido en ella abondar en toda fermosura, flo[re]cer en virtudes; e todo linaje de vanidades aborresçía". Cf. Boccaccio, De mulieribus claris, cap. XXXI de la traducción castellana impresa por Pablo Hurus en Zaragoza el 24 de octubre de 1494.

44 Cf. Boccaccio, De mulieribus claris, cap. XXXV, Pablo Hurus, Zaragoza, 1494.

45 Segunda hija de Príamo y Hécuba. Pedro de Chinchilla: "La segunda, Casandra, la cual, como en la virginal onestad floresciese, en las liberales artes más floresçía, aviente noticia de las artes e sciencias de las venideras cosas" (157), o "Casandria fue de convenible altura, mucho blanca, foyosa cara, varios ojos; deseava mucho virginidat e foía de todos los mugeriles abtos. Muchas cosas de las por venir pronosticava, como de la astrologal ciencia e en las otras liberales disciplinas fuese manifiestamente enseñada" (197). Cf. Boccaccio, De mulieribus claris, cap. XXXIII, Pablo Hurus, Zaragoza, 1494.

46 No alcanzo a fijar una lectura clara. Handr[i]a cuadra con la rima, pero no con el contexto de la materia troyana, además de ser una forzadura del título Andria de Terencio, que no se refiere al nombre de una de su protagonista, sino al lugar en el que esta reside.

$47 \quad C f$. por ejemplo, el recuento de dueñas en las estrofas 102-105 de la Comedieta de Ponza de Santillana, entre las que aparecen todas las mencionadas en la Revelación. Compárese también con 
los versos del Santillana en los Proverbios acerca de «La gentil naçión», stfs. 53 y 54: "Atenesas e tebanas | muchas son | desta mesma condiçión | e troyanas; | elenesas e argianas | e sabinas, | romanas laurentinas | e greçianas. || Fermosas e con gran sentido | fueron Vagnes, | Diana, Lucreçia, Danes, | Ana e Dido, | non se pase por olvido | Virginea, | como su grand fecho sea | conosçido" (Kerkhof, M. P. A. M. y Gómez Moreno, Á. (eds.) (2003): Marqués de Santillana. Poesías completas, Madrid, Castalia [Clásicos Castalia, 270]). O Fernán Pérez de Guzmán sobre el punto de la muerte en su Dezir muy graçioso e sotilmente fecho e letradamente fundado [que] fizo e ordenó [...] por contemplaçión de los emperadores e reis e príncipes e grandes señores que la muerte cruel mató e llevó deste mundo, e cómo ninguno non es relevado della, vv. 57-72: "Dueñas de linda apostura, | Casandra e Pulisçena, | Medea de grand cordura | e la muy fermosa Elena, | Juliana e Filomena | que tan amorosas fueron, | todas tristes padeçieron | esta espantosa pena. || Ginebra e Oriana | e la noble reina Iseo, | Minerva e Adriana, | dueñas de gentil aseo, | segund que yo estudio e leo | en escrituras probadas, | non podieron ser libradas | deste mal escuro e feo". 


\section{BIBLIOGRAFÍA CRÍTICA DE LOS TEXTOS DE SA9A}

A continuación se desglosan los textos del manuscrito en su orden, pues el texto se comprende mejor en su contexto codicológico.

[1] Fernando de Cigales:

- (1a) Epitaphium in Sepulchrum illustrissimi Hispanie principis domini ac domini nostri quod Bacalarius Fernandus de Çigales lusit ipsa die exequiarum in urbe que vulgo Trugillo ${ }^{1}$ dicitur

- (1b) El qual bachiller hizo estas coplas casy declarando los versos a los que no saben latín.

ID 4690: SA9a-0 (2x10).

\section{Ed. Ref.:}

Alcalá, Á. y Sanz Hermida, J. (1999): Vida y muerte del príncipe don Juan. Historia y literatura, Valladolid, Junta de Castilla y León.

Edita ambos textos, el segundo de los cuales no es traducción del primero, Sanz Hermida (1999: 361-363). Proporciona una traducción literal del texto latino y reconstruye el final de los últimos versos del texto castellano, deturpados en el manuscrito original.

\section{Testimonio único.}

\footnotetext{
1 En una breve nota biográfica, Vicente Beltrán sugiere para el poeta Tapia la identificación con Gonçalo Gomes de Tapia, que figuró entre los servidores de Isabel la Católica desde 1503, así como que «una familia con este apellido tenía ascendente en el gobierno municipal de Trujillo, en cuya iglesia de Santiago se enterraban». Por mi parte me limito a señalar la coincidencia de que sea Trujillo la ciudad en la que Fernando de Cigales (quizás vallisoletano), compuso sus exequias. Vid. Beltrán, V. (2002): Poesía española 2. Edad Media: lírica y cancioneros, Barcelona, Crítica [Páginas de Biblioteca Clásica, 2], p. 681. En cuanto a la indicación de Cigales de que el poema fue compuesto el día mismo de las exequias no sabemos bien si se refiere a la fecha misma del funeral y enterramiento, al alba del 5 de octubre de 1497, circunstancia harto improbable, o bien a las exequias, en el sentido de honras fúnebres, que tuvieron lugar en toda Castilla en fechas dispares. Sobre el asunto de las exequias vid. en el volumen arriba citado, pp. 197-202.
} 
[2] Fray Íñigo de Mendoza (c. 1424-c. 1508):

Fray Íñigo de Mendoza fue, que se sepa, el único hijo varón de Diego Hurtado de Mendoza y Juana de Cartagena, a la que dedicaría su Vita Christi². Nació posiblemente en Burgos, en el solar donde se asentaban sus notables antepasados y familiares, Pablo de Santa María, Alonso de Cartagena, Alvar García de Santa María, Pedro de Cartagena o la autora de la Arboleda de los enfermos, Teresa de Cartagena, por línea materna; Juan Hurtado de Mendoza (mayordomo mayor de Juan II), otro Juan Hurtado de Mendoza (prestamero mayor de Vizcaya), Ruy Díaz de Mendoza (mayordomo mayor de Juan II), Íñigo López de Mendoza o Juana de Mendoza (esposa de Gómez Manrique), por línea paterna. Su familia directa, sin embargo, nunca estuvo tan encumbrada y fray Íñigo siguió la carrera de numerosos descendientes de conversos en la segunda mitad del s. xv. Como señalan varias rúbricas de los cancioneros, Mendoza fue fraile menor, franciscano, de la Observancia. Parece ser que llevó una vida más o menos disipada en los años finales del reinado de Enrique IV, en especial en asuntos de amores. En cualquier caso, durante el reinado de los Reyes Católicos Mendoza desempeñó los cargos de predicador y limosnero de Isabel la Católica, al menos hasta 1497. Como panegirista de los Reyes Católicos escribió varios poemas políticos y alguna carta consolatoria, con motivo de la muerte de los príncipes don Juan (1497) y doña Isabel (1498). La relación de Mendoza con Fernando de Aragón no parece que fuera especialmente estrecha, pero sí con la reina Isabel, que siempre atendió en su vida. Hacia el final de ella ingresa en el convento de San Francisco de Valladolid (1500), etapa en la que interviene en las convenciones de la Observancia, representando, por ejemplo, al Vicario Provincial de la Provincia de Santoyo, fray Juan de Olmedo, e interviniendo en asuntos de importancia entre los que acaecieron a la Orden en aquellos tiempos y aquellos lugares.

\section{Bibl. Ref.:}

Whinnom, K. (1963): “El origen de las comparaciones religiosas del Siglo de Oro: Mendoza, Montesino y Román”, Revista de Filología Española, 46: 263-285.

Stern, Ch. (1965) “Fray Íñigo de Mendoza and Medieval Dramatic Ritual”, Hispanic Review 33: 197-245.

Rodríguez-Puértolas, J. (1963-1966): “Eiximenis y Mendoza: literatura y sociedad en la baja edad media hispánica", Revista Valenciana de Filología, 7: 139-174.

Rodríguez-Puértolas, J. (1970): “Leyendas cristianas primitivas en las obras de Fray Íñigo de Mendoza", Hispanic Review, 38: 368-385.

2 La madre de Íñigo de Mendoza fue ávida lectora e incluso parece que tuvo algún pespunte de bibliófila, si hacemos caso de las pocas cuentas que echaba en devolver a su tío el cronista Alvar García de Santa María un Boecio en latín y romance, escrito en pergamino, que éste le había prestado. Da el texto de la noticia Cantera Burgos, F. (1952): Alvar García de Santa María y su familia de conversos: historia de la judería de Burgos y de sus conversos más egregios, Madrid, Consejo Superior de Investigaciones Científicas [Instituto Arias Montano], p. 200. 
Macpherson, I. (1997): “Fray Íñigo de Mendoza, Francisco Delicado y dos enigmas salomónicos", en Actas del VI Congreso Internacional de la Asociación Hispánica de Literatura Medieval (1995), Lucía Megías, J. M. (ed.), Alcalá, Universidad de Alcalá de Henares, 1: 57-72.

Surtz, R. E. (2000): “Mujer-campo y escritor-sembrador en la tardía Edad Media castellana", en Actas del XIII Congreso de la Asociación Internacional de Hispanistas (Madrid, 6-11 de julio 1998), Sevilla, F. y Alvar, C. (eds.), Madrid, Editorial Castalia, 1: 232-237.

Martínez Vega, Ma. E. y Abad Pérez, A. (2002): “La orden franciscana en España, pensamiento y vida (siglo Xv)", Cuadernos de Investigación Histórica, 19: 248-265.

Severin, D. S. (2004): Del manuscrito a la imprenta en la época de Isabel la Católica, Kassel, Edition Reichenberger.

Lama, V. de (2005): “Aspectos eróticos en la poesía de Fray Íñigo de Mendoza”, Actas del IX Congreso Internacional de la Asociación Hispánica de Literatura Medieval (A Coruña, 18-22 de septiembre de 2001), La Coruña, Universidad de La Coruña/ Toxosoutos [Biblioteca Filológica, 14], 2005, 2, págs. 577-589.

Díez Garretas, Ma . J. (2006): “Nuevos datos para la biografía de Fray Íñigo de Mendoza”, en Convivio. Estudios sobre la poesía de cancionero, Beltrán, V. y Paredes, J. (eds.), Granada, Universidad de Granada [Biblioteca de Humanidades / Teoría y Crítica Literarias, 16]: 337-346.

Severin, D. S. (2007): “The Four Recensions of Fray Íñigo de Mendoza's Vita Christi, with Some Unpublished Stanzas", en From the Cancioneiro da Vaticana to the Cancionero General: Studies in Honour of Jane Whetnall, Deyermond, A. y Taylor B. (eds.), Londres, Department of Hispanic Studies/Queen Mary/University of London [Papers of the Medieval Hispanic Reseach Seminar, 60]: 225-234.

· (2a) El Vita Christi trobado

Las coplas de la Vita Christi mendocina se nos han transmitido en tres versiones Manuscritas claramente diferenciadas entre sí, tanto por su texto (extensión, variantes, etc.) como por su discurso, que pasa por tres etapas sucesivas. La primera versión se caracteriza por su agria crítica al entorno cortesano de Enrique IV de Castilla y por una también acerada crítica social. Las referencias sociales, políticas y sobre todo personales de la primera versión se suavizan en los textos que contienen la segunda versión, mientras que el texto deviene únicamente piadoso en la tercera versión. El texto conservado en SA9a pertenece a la segunda versión. Ofrezco un cuadro sinóptico de los diferentes estados textuales de la Vita Christi de Mendoza: 
[1] (c. 1467-1468): a) Cancionero de Oñate-Castañeda (HH1); b) BNP Esp. 305 (PN11) (298 coplas), muy catalanizado en su lengua y grafías; c) Cancionero de Egerton (LB3) (244 coplas); $\mathrm{d}^{*}$ ) Cancionero de Eugenio Montes: se refiere a él, a través de una nota de Dámaso Alonso, Rodríguez Puértolas [1968: 88], al cual no le fue permitida su consulta.

[2] Poco después de 1468: a) Escorial K-III-7 (EM6) (393 coplas); b) Cancionero de Vindel (NH2) (71 stf.); c) BUS 2139 (SA4) (2 textos); d) BUS 2762 (SA9a); e) Lázaro Galdiano, 30 (ML1).

Rodríguez Puértolas no tuvo conocimiento de SA4 en la confección de su estudio de 1968, que recogía las aportaciones bibliográficas de Whinnom y Pérez Gómez, además del resto de los estudios anteriores a éstos. Con ello se pierden dos testimonios de gran valor, dos versiones de la Vita Christi, distintas, en una misma compilación. Un análisis somero de las dos versiones de la VC que contiene SA4 manuscrito me confirma que la primera es claramente distinta de SA9 (probablemente emparentada con EM6), mientras que la segunda coincide, salvo variaciones gráficas y algunos errores mecánicos, con SA9 ${ }^{3}$. De hecho, considero que el copista de la Vita Christi de SA9 se sirvió de la sección mendocina de SA4 o bien del texto, que estaría perdido, en el que se basó SA4. A falta de las conclusiones definitivas del estudio detallado que estoy llevando a cabo, las coplas indicadas en la tabula crítica que olvidó el copista de SA9 refuerzan la idea de que SA9 se basa en SA4 y no al contrario, al tiempo que el estado lingüístico de SA9, con respecto a SA4, me parece más moderno.

[3] 1482 et passim: a) Zamora: Centenera, 5 de enero de 1482; b) Zaragoza: Hurus y Planck, 1482?; c) Zamora: Centenera, 1483-84?; d) Zaragoza: Hurus, 27 de noviembre de 1492; e) Zaragoza: Hurus 1495 (reimpresión de la antología religiosa de 1492); f) Sevilla: Meinard, Ungut y Polono, 1499; g) Sevilla: Polono, 1502? (fragmentario); h) Sevilla: Cromberger, 1506; i) Sevilla: Cromberger, 23 de agosto de 1546.

ID 0269: BC3-7 (97v-98v) sin título (21x10...), EM6-1 (1r-97r) (374 coplas), HH157 (314v-344v) (314 coplas), LB3-23 (59r-82v) (294 coplas); ML1-1 (2r-41r) (+/- 450

\footnotetext{
3 Las descripciones de los ejemplares manuscritos e impresos de Rodríguez Puértolas no son, bibliológicamente, lo detalladas que podría desearse. La que atañe a SA9a es especialmente confusa, ya que el desglose de contenidos aparece desordenado e incluso escamoteado en alguno de sus ítems con respecto al original salmantino. De hecho Rodríguez Puértolas afirma en la nota 1 de la página 118 que 'b1', esto es, EM6, «es la única copia conocida de la segunda [redacción]». Este aserto parece revelar que Rodríguez Puértolas no llegó a consultar directamente SA9, del mismo modo que no conoció SA4. El modo en que entiende Rodríguez Puértolas el texto de Mendoza es muy discutible: considera como redacción definitiva del autor la impresa en 1482 por Centenera y da prioridad a este texto, que llama 'A'. Sus lecturas son comparadas con ' $\mathrm{a} 1^{\prime}$ ' $\mathrm{y}$ ' $\mathrm{a} 2^{\prime}$ ' $\mathrm{y}$ ' $\mathrm{b} 1^{\prime}$ ', casi exclusivamente, siglas que se corresponden con PN1, LB3 y EM6. El descuido de esta sección, en un estudio que no tenía por fin principal la edición de las coplas, a lo que parece, se hace notar en la falta de elaboración de un auténtico texto crítico de la Vita Christi, tarea cada vez más urgente.
} 
coplas), NH2-1 (1-19) sin título (71x10...), PN11c-8 (118r-195v) (244 coplas), SA4-10 (71r-119r) (420 coplas, 5), SA4-5 (5v-30r) sin título (290x10), SA5-2 (158v) (10vv... $)^{4}$, SA9a-1 (1r-27r (420 coplas, 5), 82*IM-1 (...a2r-e3r) (341 coplas), 82IM-1 (1r-33v) (341 coplas), 83*IM-1 (1r-30r) (391 coplas), 95VC-1 (2r-31r) (341 coplas), 02*VC-1 (...e1r-e8v) Acéfalo (...5, 78x10), 06VC-1 (1r-36r) (341 coplas)

\section{Ed. ref.:}

Rodríguez Puértolas, J. (1968): Fray Íñigo de Mendoza y sus "Coplas de Vita Christi», Madrid, Gredos [Biblioteca Románica Hispánica, 4. Textos].

Rodríguez Puértolas, J. (1968): Fray Íñigo de Mendoza. Cancionero, Madrid, Espasa-Calpe [Clásicos Castellanos, 163].

Pérez Gómez, A., nota preliminar, (1975): Vita Christi fecho por coplas (¿1482?), Valencia, Imprenta Soler/Ediciones "la fonte que mana y corre" [Incunables Poéticos Castellanos, 14].

Massoli, M. (1977): Fray Íñigo de Mendoza. «Coplas de Vita Christi», Messina/Florencia, Casa Editrice D’Anna [Università degli studi di Firenze. Facoltà di Magisterio/ Istituto Ispanico. Publicazioni dell'Istituto Ispanico].

(2b) "[Coplas] para el rey nuestro señor"

ID 7815 A 0269: SA4-11 (119r-120v), SA9a-1a (25v-26v) (12x10).

· (2c) "Estas son las que ha de tener el frayle"

ID 2998 A 0269: HH1-58 (345v-346v) (7x10, 5), SA4-12 (120v-121r); MN19-89 (538r-539r) (4x10), SA9a (26v-27r) ${ }^{5}$.

•(2d) "Estas son del primer Rétulo de la muerte contra los grandes"

ID 4332 A 0269: SA4-13 (121r-v), SA9a-2a $(26 v-27 r)(3 \times 10,5)$.

4 Versos utilizados como oración por el copista, como puede apreciarse por la transcripción de éstos y del explicit. Cierran la sección dedicada a Ausiàs March, si bien en 157v y 158r se han copiado unos versos de Mosen Llors Pardo y de Jordi de Centelles: «Aclara soll diuinal la cerrada niebla | escura que . n ell linage humanall | por la culpa paternall | desdell comiençołt nos dura | despierta la voluntat, endereça la mamoria por | que sin contraridat a tu alta magestat | se cante deuida gloria». || "Quis escripsit escribat, senpre cum domjno viuat, dominicus vocatur, qujs escripsit benedicatur» (158v).

5 Dutton hace referencia a SA5 para los versos contenidos en los ítems 2c-2e. El único resto de las composiciones de Mendoza que en este cancionero se conservan son los primeros diez versos de la Vita Christi. 
· (2e) "La muerte en el otro Rótulo para esfuerço de la virtud fatigada"

ID 7814 A 0269: HH1-59 (346v) (3x10), SA4-14 (121v-122r), SA9a 3 (27r).

·(2f) Coplas de la Verónica

ID 2893: ML1-4 (...72r-81v) Acéfalo (...92x10); SA9a4 (27v-33v) (108x10); 83*IM10 (59v-66r) (98x10); 95VC-4 (54r-60v) (99x10). Versión 3641 (Fray Ambrosio Montesino (1444?-1514?) ). El Cancionero de Oñate-Castañeda (HH1), contiene una versión distinta: incluye una estrofa final nueva que no pudo leer Rodríguez-Puértolas (1970), pero sí Garcia (1979: 174), donde se afirma la autoría de fray Ambrosio Montesino. La cuestión de la paternidad permanece todavía hoy en el alero.

\section{Ed. Ref.:}

Rodríguez Puértolas, J. (1968): Fray Íñigo de Mendoza. Cancionero, Madrid, Espasa-Calpe [Clásicos Castellanos, 163].

Bibl. Ref.:

Rodríguez-Puértolas, J. (1970): "Montesino y Mendoza: un caso de plagio literario", Bulletin of Hispanic Studies, 47: 10-18.

Garcia, M. (1979): “Les Coplas a la Verónica”, Iberica, 2: 171-180.

[3] Comendador Román:

Los datos que se han podido agavillar sobre la biografía del Comendador Román son muy parcos. La mayor parte de ellos son de carácter deductivo y carecen de base cierta, ya que las poesías de escarnio intercambiadas entre Antón de Montoro y el Comendador, en cuanto tópico literario, no deben empujar a incluir a Román en la lista de los moriscos, los judíos o los conversos. Es posible que sirviera a García Álvarez de Toledo, duque de Alba, en años próximos a 1465, según se intuye de una canción a él enderezada. Las Coplas de la Pasión y Resurrección (c. 1480-c. 1492) tienen como destinatario-dedicatario a los Reyes Católicos, lo que invita a pensar, también, en el contacto de Román con la corte real, hecho al que hay que añadir su colaboración en el corpus de literatura funeraria por la muerte del príncipe don Juan: Décimas sobre el fallecimiento del príncipe nuestro señor (realizadas con anterioridad a noviembre de 1497, por datos internos). De entre las posibles atribuciones biográficas Mazzocchi entiende 
como la más plausible la que él mismo propone, que el Comendador sea el contino toledano Diego Román, del cual se conserva una escasa pero relevante documentación que lo pone en relación con el aparato administrativo y judicial de los Reyes Católicos, y donde se reconocen sus servicios como hombre de armas, por ejemplo. Su período de creación poética se sitúa, aproximadamente, entre 1465 y 1500, y sus composiciones abarcan la poesía religiosa, la satírica y la amorosa.

\section{Bibl. Ref.:}

Whinnom, K. (1963): “El origen de las comparaciones religiosas del Siglo de Oro: Mendoza, Montesino y Román”, Revista de Filología Española, 46: 263-285.

Solá-Solé, J. Mª (1983): “El Comendador Román y los marranos”, en Sobre árabes, judíos y marranos y su impacto en la lengua y literatura españolas, Barcelona, Puvill: 225242.

Mazzocchi, G. (1985): "Para la edición crítica de las Coplas de la Pasión con la Resurrección del Comendador Román", en Literatura hispánica, Reyes Católicos y Descubrimiento. Actas del Congreso Internacional sobre Literatura hispánica en la época de los Reyes Católicos y el Descubrimiento (1986), Criado de Val, M. (dir.), Barcelona, Promociones y Publicaciones Universitarias: 285-294.

Mazzocchi, G. (1988): “La Tragedia trobada de Juan del Encina y las Décimas sobre el fallecimiento del príncipe nuestro señor del comendador Román: dos textos frente a frente", en Il Confronto Letterario. Quaderni del Dipartimento di Lingue e Letterature Straniere Moderne dell'Università di Pavia, 5.9: 93-123.

Lope, M. de (1990): “Sur un débat entre Antón de Montoro et le Commandeur Román”, en Écrire à la fin du Moyen Âge. Le pouvoir et l'écriture en Espagne et en Italie (14501530), Aix-en-Provence, Publication de l'Université de Provence: 253-267.

Mazzocchi, G. (1990), "Poesía amorosa del Comendador Román”, Écrire à la fin du Moyen Âge. Le pouvoir et l'écriture en Espagne et en Italie (1450-1530), Aix-enProvence, Publication de l'Université de Provence: 43-77.

· (3a) "Los siete gozos y cuchillos de nuestra señora"

ID 4276: SA4-17 (149r-173v) (40x10), SA9a-5 (33v-36r).

\section{Ed. Ref.:}

Álvarez Pellitero, Ana María (1984): “Coplas desconocidas del Comendador Román”, Boletín de la Biblioteca Menénde Pelayo, 60: 99-114. 
- (3b) Coplas a la cena de Nuestro Señor

Son dos los testimonios manuscritos que conservamos de las Coplas del Comendador Román: las del Cancionero sevillano de Nueva York (NH3), un intervento creativo sullo testo, según Mazzocchi (1990: 71) del que no es posible decidir si corresponde a una revisión del propio Román o bien a una modificación independiente. Este texto queda fuera del stemma propuesto por Mazzochi. Éste, en su edición crítica, plantea dos ramas: la primera contiene a SA9, y la segunda los textos impresos descendientes de un testimonio perdido $\beta$. Los impresos se bifurcan a partir de $\beta$ a pesar de proceder ambos de la imprenta toledana de Juan Vázquez, el primero de 1486, sin la Resurrección, y el segundo posterior a mayo de 1491, cuyo único ejemplar contiene correcciones manuscritas al texto, del que desciende la impresión Zamorana de Antonio de Centenera, c. 1493, estampa que comparte algunos llamativos errores comunes con NH3.

ID 4230 I 4327: SA9a-6 (41r-42v) (19x11); 90*CR-1 (2r-3v) (18x11); 4230-4235: $11^{*} \mathrm{CR}-1(i ?)$

ID 4327: NH3-1 (1r- ??r) (17x11), SA9a-7 (42v-44r), 90*CR-2 (a6r-c8r).

ID 4231 I 4326: NH3-2 (2v-16r) (6x11), SA9a-8 (44r-v), 90*CR3 (a5v-a6r). Después de esta obra los Reyes nuestros señores le tornaron a mandar que acabase toda la pasyón desde este paso de la çena y por su mando comiença.

· (3c) Coplas a la Pasión de Nuestro Señor

ID 4326: SA9a-9 (44v-59r) (173×11), 90*CR-4 (a6r-c8r).

·(3d) Coplas a la Resurrección de Nuestro Señor

ID 4232 I 4325: SA9a-10 (59r-v) (4x11), 90CR-5 (d1r).

ID 4325: NH3-3 (16v-32v) (163x11), SA9a-11 (59v-73r), 90*CR-6 (25v-42v).

\section{Ed. Ref. :}

Mazzocchi, G. (1990): Comendador Román. "Coplas de la Pasión con la Resurrección», Florencia, La Nuova Italia [Pubblicazioni della Facoltà di Lettere e Filosofia dell’Università di Pavia, 61]. 
[4] Anónimo:

Admito como buena la identificación que sugirió Víctor García de la Concha [1983: 230] de Lope de Salazar († 24 de febrero de 1463) con el discípulo del reformador franciscano fray Pedro de Villacreces. Una revisión del legado escrito de Lope de Salazar no invita, sin embargo, a considerar a fray Lope de Salinas (o de Salazar) como el autor de la Revelación, pese al uso de la primera persona, que no es más que un recurso retórico característico de las visiones y los somnia.

\section{Bibl. Ref.:}

Valero Moreno, J. M. (2005): “La persistencia alegórica. Un poema narrativo dantesco en el corpus decancioneros salmantinos:la Revelación quefue mostrada Lope de Salazar por un ángel (BUS ms. 2762)", en Actes del X Congrés Internacional de l'Associació Hispànica de Literatura Medieval, Alemany, R., Martos, J. Ll. y Manzanaro, J. M. (eds.), Alicante, Universidad de Alicante [Symposia Philologica], 2: 1539-1557.

·(4a) Revelación que fue mostrada a Lope de Salazar por un ángel

ID 4278: SA9a-12 (57x12).

Testimonio único.

[5] Gonzalo de Tapia

Este poeta tardío, a caballo entre los siglos Xv y xvI, estuvo muy vinculado a los Mendoza, lo que podría justificar el amago de aparición en este cancionero. Aunque apenas sabemos nada de su biografía es probable, por las dedicatorias de sus poemas, que Tapia hubiera morado en Salamanca alguna vegada. Juan del Encina puso música a una de sus canciones: "Pues que jamás olvidaros". Por otro lado, SA9 es el único cancionero que da el nombre de 'Gonzalo' al Tapia a secas del resto. El texto (15x11) puede leerse en LB1, 11CG y 14 CG. Doy las rúbricas para su cotejo: 'Otras suyas en que dize que estando sin amores vino amor y le mandó que los toviese y dale una señora a quien mucho tienpo avía començado a servir y dexóla creyendo ser della malgradeçido. Comiença la obra.' [LB1]; 'Comiençan las obras de Tapia y esta primera es una en que dize que estando sin amores le buscó amor y le mandó que los toviesse y dale una señora a quien sirva y es a quien mucho tiempo avía que començó a servir y dexóla temiendo que sería mal gradescida.' [11CG y 14 CG]. 
(5a) Coplas de Gonzalo de Tapia en que dyze cómo estando sin amores le buscó amor y le mandó los tuviese.

\section{FUENTES MANUSCRITAS E IMPRESAS ${ }^{6}$}

BC3: Barcelona: Biblioteca de Catalunya, ms. 1967. Cancionero de Pedro Antonio de Aragón, c. $1480^{7}$.

EM6: San Lorenzo de El Escorial: Biblioteca del Monasterio de San Lorenzo de El Escorial, ms. K-III-7. Obras de fray Íñigo de Mendoza y otros, c. $1485^{8}$.

HH1: Harvard: University Library of Harvard, Houghton, ms. fMS Sp 97. Cancionero de Oñate-Castañeda, c. $1485^{9}$.

LB1: Londres: British Library, ms. Add. 10431. Cancionero de Rennert, c. $1510^{10}$.

6 Sigo, con ligeras modificaciones y alguna corrección de erratas, en su caso, las siglas y disposición de Dutton, B. (1991): El Cancionero del siglo XV (c.1360-1520), Salamanca, Biblioteca Española del siglo Xv/ Universidad de Salamanca [Serie Maior, 1-7].

7 Kerkhof, M. P. A. M. (1979): “El ms. 80 de la Biblioteca Pública de Toledo y el ms. 1967 de la Biblioteca de Catalunya, de Barcelona, dos códices poco conocidos", Revista de Archivos, Bibliotecas y Museos, 82.1: 17-58.

8 Fernández, B. (1904): La Ciudad de Dios, 63: 586-593; Zarco Cuevas, J. (1926): Catálogo de los manuscritos castellanos de la Real Biblioteca de El Escorial, Madrid, Imprenta Helénica, 2: 175-184; Whinnom, K. (19681969): "Ms. Escurialense K-III-7: el llamado Cancionero de Fray Íñigo de Mendoza", Filología, 13: 161-172 y (1977 [1979]) “Fray Íñigo de Mendoza, Fra Jacobo Maza, and the Affiliation of Some Early Mss of the Vita Christi", Annali di Ca'Foscari, 16: 129-139.

9 Ed. Severin, D. S., introducción de Garcia, M. (1972), Madison: Hispanic Seminary of Medieval Studies. Vid. Rodríguez Puértolas, J. (1972): “El Cancionero de Oñate-Castañeda”, en De la Edad Media a la Edad Conflictiva, Madrid, Gredos: 55-72 y Garcia, M. (1978) y (1979) "Le Chansonnier d'Oñate y Castañeda", Mélanges de la Casa de Velázquez, 14: 107-208 y 15: 207-239.

10 Rennert, H. A. (1899): “Der spanische Cancionero des British Museum (Ms. Add. 10.431). Mit Einleitung und Anmerkungen zum erstenmal herausgegeben", Romanische Forschungen, 10: 1-176; Jones, R. O. (1961): "Encina y el cancionero del British Museum", Hispanófila, 4: 1-21; Alvar, C. (1991): "LB1 y otros cancioneros castellanos", en Lyrique romane médiévale: la tradition des chansonniers. Actes du Colloque de Liège (1989), Tyssens, M. (ed.), Lieja, Bibliothèque de la Faculté de Philosophie et Lettres [BFPL, 258]: 469-500; Toro Pascua, Mª. I. (1995): “Algunas notas para la edición de las poesías de Guevara”, en Medioevo y Literatura. Actas del V Congreso de la Asociación Hispánica de Literatura Medieval (1993), Paredes Núñez, J. (ed.), Granada, Universidad de Granada, 4: 389-403; Stefano, G. di (1996): "Romances en el Cancionero de la Bristish Library, Ms. Add. 10431", en Nunca fue pena mayor. Estudios de Literatura Española en homenaje a Brian Dutton, Menéndez Collera A. y Roncero López, V. (eds.), Cuenca, Universidad de Castilla la Mancha: 239-253; Toro Pascua, Ma . I. (1996) «La Sepultura de amor de Guevara. Edición crítica», en Nunca fue pena mayor. Estudios de Literatura Española en homenaje a Brian Dutton, Menéndez Collera A. y Roncero López, V. (eds.), Cuenca, Universidad de Castilla la Mancha: 663-689; Moreno, M. (1997): "Sobre la relación de LB1 con 11CG y 14 CG", en Actas del VI Congreso de la Asociación Hispánica de Literatura Medieval, Lucía Megías, J. M. (ed.), Alcalá de Henares, Universidad de Alcalá, 2: 1069-1083; Moreno, M. (1999): "Las variantes en el Ms. Add. 10431 de la British Library (LB1)", en Actes del VII Congrés de la Asociación Hispánica de Literatura Medieval, Fortuño Llorens, S. y Martínez Romero, T. (eds.), Castellón de la Plana, Publicacions de la Universitat Jaume I, 3: 37-48; Moreno, M. (2000): “Una nueva edición de LB1", Actas del VIII Congreso de la Asociación Hispánica de Literatura Medieval, Freixas, M., Iriso, S. y Fernández, L. (eds.), Santander, Consejería de Cultura del Gobierno de Cantabria/ Año Jubilar Le- 
LB3: Londres: British Library, Egerton, ms. 939. Cancionero de Egerton, c. $1475^{11}$.

ML1: Madrid: Biblioteca de la Fundación «Lázaro Galdiano», ms. 30. Obras de fray Íñigo de Mendoza, $1498^{12}$.

MN19: Madrid: Biblioteca Nacional de Madrid, ms. 4114. Posible copia de ZZ6 (Gallardo III, 2434) continente obras de Pero Guillén de Segovia y otros, s. XVIII ${ }^{13}$.

NH2: Nueva York: Hispanic Society of New York, ms. B 2280. Cancionero de Vindel, c. 1475-c. $1480^{14}$.

NH3: Nueva York: Hispanic Society of New York, ms. B 2486, fols. 1-37: Obras del siglo XV. Cancionero Sevillano de Nueva York, c. $1560^{15}$.

baniego/Asociación Hispánica de Literatura Medieval, 2: 1327-1339; Moreno, M. (2001): “Transmisión y estructura en LB1. Pliegos sueltos y unica", en Canzonieri iberici, Botta, P., Parrilla, C. y Pérez Pascual, I. (eds.), Noia, Università di Padova/Toxosoutos/Universidade da Coruña, 2: 287-307; Botta, P. (2005): "Las fiestas de Zaragoza y las relaciones entre LB1 y 16RE (con un Apéndice de Juan Carlos Conde, LB1: hacia la historia del códice)", Incipit, 22: 3-51; Moreno, M. (2005): “La variante en LB1. Tres calas en el Ms. Add. 10.431 de la Bristish Library", en Los cancioneros españoles: materiales y métodos, Moreno, M. y Severin, D. S. (eds.), Londres, Department of Hispanic Studies/Queen Mary/University of London [Papers of the Medieval Hispanic Research Seminar, 43]: 91-112.

11 Severin, D. S., ed. (2000): Two Spanish Songbooks. The «Cancionero Capitular de la Colombina» (SV2) and the «Cancionero de Egerton», Liverpool y Sevilla: Liverpool University Press [Hispanic Studies. Textual Research and Criticism, 11]/Institución Colombina; Elia, P. (1982): "La Pasión de nuestro señor Jesucristo (Cancionero Egerton, ms. 939)", en Studia Philologica Salmanticensia, 6: 67-79; Severin, D. S. (1985): “El ynfante Epitus: The Earliest Complete Castilian Version of the Dialogue of 'Epictetus and the Emperor Hadrian”, Bulletin of Hispanic Studies, 62: 25-29; Severin, D. S. (1994): “Cancionero: un género mal-nombrado", Cultura Neolatina, 54: 95-105; Severin, D. S. (1997): “Two Letters of Devotional Advice to Nuns in the Cancionero de Egerton (Dutton LB3)", en Spain and its Literature: Essays in Memory of E. Allison Peers, Mackenzie A. L. (ed.), Liverpool: Liverpool University Press-MHRA: 65-76.

12 Yeves, J. A. (1998): Manuscritos españoles de la biblioteca "Lázaro Galdiano", Madrid: Ollero \& Ramos/ Fundación "Lázaro Galdiano", 1, sub. nº 312.

13 Lang, H. R. (1908): “The so-called Cancionero de Pero Guillén de Segovia", Revue Hispanique, 19: 51-81; John G. Cummins, J. G. (1973): "Pero Guillén de Segovia y el ms. 4114", Hispanic Review, 41: 6-32; Marino, N. F., (1978): “The Cancionero de Pero Guillén de Segovia and ms. 617 of the Royal Palace Library", La Corónica, 7.1: 20-23; (1984): Inventario general de manuscritos de la Biblioteca Nacional, Madrid, Ministerio de Cultura-Dirección General del Libro y Bibliotecas, 10.

14 Rodríguez-Moñino, A. y Brey Marino, M. (1965): Catálogo de los manuscritos poéticos castellanos existentes en la Biblioteca de The Hispanic Society of America (siglos XV, XVI, XVII), Nueva York, The Hispanic Society of America, 1: 42-48; Ramírez de Arellano y Lynch, R. W. (1970): “The Cancionero de Vindel, ms. B2280 in the Library of the Hispanic Society of America, New York: Critical Edition and Text»; Ramírez de Arellano y Lynch, R. W. (1976): La poesía cortesana del siglo XV y el "Cancionero de Vindel". Contribución al estudio de la temprana lírica española. Estudio preliminar y edición crítica de los textos únicos del Cancionero, Barcelona, Vosgos; Faulhaber, Ch. B. (1983) Medieval Manuscripts in the Library of the Hispanic Society of America. Religious, Legal, Scientific, Historical and Literary Manuscripts, Nueva York: The Hispanic Society of New York, 2 vols.

15 Frenk Alatorre, M. (1962): “El Cancionero sevillano de la Hispanic Society (c. 1568)”, Nueva Revista de Filología Hispánica, 16: 355-394; Rodríguez-Moñino, A. y Brey Marino, M. (1965): Catálogo de los manuscritos poéticos castellanos existentes en la Biblioteca de The Hispanic Society of America (siglos XV, XVI, XVII), Nueva York, The Hispanic Society of America, 1: 51-73; Faulhaber, Ch. B. (1983) Medieval Manuscripts in the Library of the Hispanic Society of America. Religious, Legal, Scientific, Historical and Literary Manuscripts, Nueva York: The Hispanic Society of New York, 2 vols.; Frenk Alatorre, M., Labrador Herrero, J. J. y Franco, R. A. di (eds.) (1996): Cancionero sevillano de Nueva York, Sevilla, Universidad de Sevilla. 
PN11: París: Bibliothèque Nationale de France, ms. Esp. 305. Cancionero castellanocatalán, c. $1470^{16}$.

SA4: Salamanca: Biblioteca Universitaria de Salamanca, ms. 2139. Obras de Santillana, Mendoza, Ferrol, etc., c. $1485^{17}$.

SA5: Salamanca: Biblioteca Universitaria de Salamanca, ms. 2244. Obras de Ausiàs March, Mena, etc., $1485^{18}$.

SA9a: Salamanca: Biblioteca Universitaria de Salamanca, ms. 2762. Obras de Mendoza, Román, etc., c. $1500^{19}$.

82*IM: FIM, Cancionero, ¿Zaragoza: Pablo Hurus y Hans Planch, 1482?20.

82 IM: FIM, Vita Christi, etc., Zamora: Centenera, 21-1-1482.

83*IM: FIM, Cancionero, ¿Zamora: Centenera, 1483?21.

95 VC: FIM, Vita Christi, etc., Zaragoza: Pablo Hurus, 10-10-1495.

02*VC: FIM, Vita Christi, Sevilla, ¿1502?

06 VC : FIM, Vita Christi, Sevilla : Cromberger, 1506

90*CR: CR, Coplas de la pasión, Toledo, ¿1490?22.

11CG: Tapia. Hernando del Castillo, Cancionero General, Valencia, 151123.

16 Morel-Fatio, A. (1892) : Catalogue des manuscrits espagnols et des manuscrits portugais de la Bibliothèque Nationale, París, Imprimerie Nationale, 3 vols.

17 Cátedra, P. M. (2001): Poesía de Pasión en la Edad Media. El "Cancionero" de Pero Gómez de Ferrol, Salamanca, Semyr [Documenta, 1]. Toro Pascua, Mª. I. (2003): "Los cancioneros salmantinos (SA1-SA14)", en Actas del II Congreso Internacional "Cancionero de Baena", Serrano Reyes, J. L. (ed.), Baena, Ayuntamiento de Baena, 1: 525-535; Lilao Franca, O. y Castrillo González, C. (2003): Catálogo de manuscritos de la Biblioteca Universitaria de Salamanca. II. Manuscritos 1680-2777, Salamanca, Universidad de Salamanca [Obras de Referencia, 13].

18 Lilao Franca, O. y Castrillo González, C. (2003): Catálogo de manuscritos de la Biblioteca Universitaria de Salamanca. II. Manuscritos 1680-2777, Salamanca, Universidad de Salamanca [Obras de Referencia, 13].

19 García de la Concha, V. (1983): “Un cancionero salmantino del siglo xv: el ms. 2762”, en Homenaje a José Manuel Blecua, Madrid, Gredos: 217-235; Lilao Franca, O. y Castrillo González, C. (2003): Catálogo de manuscritos de la Biblioteca Universitaria de Salamanca. II. Manuscritos 1680-2777, Salamanca, Universidad de Salamanca [Obras de Referencia, 13].

20 Las ediciones de poemas de fray Íñigo de Mendoza, además de por Julio Rodríguez Puértolas, han sido estudiadas por Antonio Pérez Gómez (1959): “Notas para la bibliografía de fray Íñigo de Mendoza y Jorge Manrique", Hispanic Review, 27: 30-41 y Keith Whinnom (1962): "The Printed Editions and the Text of the Works of fray Íñigo de Mendoza", Bulletin of Hispanic Studies, 39: 161-172. Hay edición facsímil de 82*IM: Antonio Pérez Gómez (1975): Vita Christo fecho por coplas, Cieza (Murcia), La fonte que mana y corre [Incunables Poéticos Castellanos, 14]. El último estudio que conozco es el de Dorothy S. Severin, Del manuscrito a la imprenta en la época de Isabel la Católica, Kassel: Reichenberger, 2004, que dedica su última sección a revisar las tres versiones de la Vita Christi.

21 Vid. Rivera, G. M y Trienens, R. J. (1979), “The Cancionero de Íñigo de Mendoza: An Unknown FifteenthCentury Edition in the Library of Congress", La Corónica, 8: 22-28.

22 Thomas, H. (ed. facs.) (1936), Comendador Román. Coplas de la Pasión con la Resurrección, Londres, British Museum; Pérez Gómez, A. (ed. facs.) (1955), Comendador Román. Coplas de la Pasión con la Resurrección, Murcia: La fonte que mana y corre [Incunables Poéticos Castellanos, 4].

23 Edición facsímil de Rodríguez Moñino, A. (1958): Madrid, Real Academia Española, y (1959): Suplemento al «Cancionero General» de Hernando del Castillo (Valencia, 1511) que contiene todas las poesías que no 
14CG: Tapia. Hernando del Castillo, Cancionero General, Valencia, 1514.

figuran en la primera edición y fueron añadidas desde 1514 hasta 1557, Madrid, Castalia. 